\title{
PUBLIC INSURANCE AND MORTALITY: EVIDENCE FROM MEDICAID IMPLEMENTATION*
}

\author{
Andrew Goodman-Bacon
}

November 25, 2015

\begin{abstract}
:
This paper provides new evidence that Medicaid's introduction reduced mortality among nonwhite infants and children in the 1960s and 1970s. Mandated coverage of all cash welfare recipients induced substantial cross-state variation in the share of children immediately eligible for the program. Before Medicaid, higher- and lower-eligibility states had similar infant and child mortality trends. After Medicaid, public insurance utilization increased and mortality fell more rapidly among children and infants in high-Medicaid-eligibility states. Mortality among nonwhite children on Medicaid fell by 20 percent, leading to a reduction in aggregate nonwhite child mortality rates of 11 percent.
\end{abstract}

JEL Codes: I13, J10, N32.

\section{Contact Information:}

School of Public Health, University of California, Berkeley, 50 University Hall, Berkeley, California 94720; (510) 473-0791; ajgb@berkeley.edu

\footnotetext{
${ }^{*}$ This project was generously supported by the NICHD (T32 HD0007339) UM Population Studies Center Traineeship, the University of California-Berkeley's Center on the Economics and Demography of Aging (NIA 2P30AG012839), and the Robert Wood Johnson Foundation's Health Policy Scholars program. The opinions and conclusions expressed herein are solely those of the author and should not be construed as representing the opinions or policy of any agency of the Federal government. I am grateful to Doug Almond, Hilary Hoynes, and Diane Schanzenbach for sharing the Regional Economic Information System (REIS) data for the 1959 to 1978 period and the Food Stamp roll-out data; Amy Finkelstein for sharing the American Hospital Association (AHA) Annual Survey data from 1948 to 1974; and Jean Roth for sharing the AHA data from 1976 to 1990. I am also grateful for helpful comments from Martha Bailey, John Bound, Tanya Byker, Kitt Carpenter, Jamein Cunningham, John DiNardo, Nic Duquette, Hilary Hoynes, Brian Kovak, Helen Levy, Sarah Miller, Lisa Neidert, Sayeh Nikpay, Holly Painter, Gary Solon, Laura Wherry and seminar participants at Northwestern University, the University of California Davis, the University of California, Berkeley, and the 2015 NBER DAE Spring Program Meeting.
} 
The establishment of means-tested public health insurance-Medicaid—in 1965 was among the largest public efforts in United States history to improve the health of the poor. The program's architects predicted "the beginning of a new era in medical care for low income families...the assurance of complete, continuous, family centered medical care of high quality to persons who are unable to pay for it themselves," (Department of Health, Education and Welfare 1967a). Today, Medicaid is the most common way that poor families pay for medical care, especially for children (Cohen and Martinez 2013). In 2011, it covered 60 million people, including 4 in 10 children, and cost federal and state governments 414 billion dollars—-the third most expensive transfer program behind Medicare and Social Security (Center for Medicare and Medicaid Services 2012; Kaiser Family Foundation 2013).

While Medicaid's costs are large and controversial, its benefits in terms of health have been harder to quantify. Quasi-experimental research finds that legislative expansions of Medicaid eligibility led to large reductions in mortality for infants, children, teens and adults (Currie and Gruber 1996a; b; Sommers et al. 2012; Wherry and Meyer 2013). The corresponding increases in any insurance coverage are relatively small, however (see Card and Shore-Sheppard 2004), leaving considerable uncertainty about the mechanism for these effects. ${ }^{1}$ Adding to this uncertainty is that the Oregon Health Insurance Experiment (OHIE) — the highest-quality study of Medicaid's effect on health—finds no evidence of improvements in clinical health measures (Baicker et al. 2013) or one-year mortality (Finkelstein et al. 2012) for adults. The absence of significant results in the OHIE, however, may reflect its short time horizon, the characteristics of its sample, or its statistical power. Consequently, for a variety of reasons, decades of research on Medicaid has provided limited evidence on the program's health effects.

This paper uses the introduction of Medicaid between 1966 and 1970 and the federal requirement that states cover all cash welfare recipients (the "categorically eligible") to provide new estimates of its

\footnotetext{
${ }^{1}$ Explanations for such large magnitudes include underreporting of Medicaid coverage (Card et al. 2004), additional health effects from increased disposable income (Leininger et al. 2012), investments due to increased provider revenue (Finkelstein 2007), increased take-up of other transfer programs (Bitler and Currie 2004), or omitted variables (Dave et al. 2008).
} 
effects on the health of the poor. The statutory link between welfare receipt and Medicaid eligibility motivates two aspects of my analysis. First, it generated wide variation across states in welfare-based eligibility due to long-standing, institutional differences. Second, nonwhite children were six times as likely to be eligible for Medicaid under the categorical eligibility provision as white children (18 percent versus 3 percent), and four times as likely as nonwhite adults (4.5 percent), so the analysis has the most power to identify effects of Medicaid implementation for nonwhite children.

I estimate Medicaid's effects in a difference-in-differences framework that compares infant and child mortality rates before and after Medicaid implementation (first difference) between higher- and lowereligibility states (second difference). State-level mortality rates by age, race, and cause of death from 1950 to 1979 facilitate an event-study analysis of Medicaid's longer-run effects up to nine years after implementation. This empirical strategy, based on "dose-response” type comparisons across states with different eligibility levels, obviates the need for comparisons between states that implemented Medicaid earlier and later, which differed in their pre-Medicaid mortality trends.

The results imply that Medicaid was very effective in achieving one of its primary goals: “prevent[ing]...premature death” (Department of Health, Education and Welfare [DHEW]1967a). After Medicaid's introduction, higher-eligibility states experienced dramatic decreases in infant and child mortality rates relative to lower-eligibility states. The effects persist for nine years and are strongest and most precise for nonwhite children who qualified for and used Medicaid. Infant mortality reductions come from improved acute care at birth: they are concentrated in the first few hours of life, there are no improvements in measure of fetal health (birth weight or sex ratios), and auxiliary evidence suggests increases and improvements in hospital care. Child mortality reductions come largely from improved care for infectious disease: they are largest for youngest, most susceptible children, and for causes with effective treatments in the 1960s and 1970s. Newly-entered data on public health insurance programs 
from 1963 to 1976 verify that welfare-based Medicaid eligibility led to meaningful increases in children's public health insurance use, the primary mechanism for the mortality effects. The estimates imply that Medicaid reduces the mortality of children who use it by 20 to 30 percent.

Several pieces of evidence support a causal interpretation of these estimates. First, levels and trends in state characteristics in the early 1960s including poverty, mortality, medical resources, and private insurance rates are uncorrelated with differences in welfare-based eligibility when Medicaid was implemented. Moreover, the results from an event-study specification (Jacobson et al. 1993) show directly that mortality rates in higher- and lower-welfare states did not trend differently for 16 years prior to Medicaid. Second, there is little evidence of differential changes after Medicaid in other programs that could affect mortality such as Food Stamps, Community Health Centers, or Head Start. There is also little evidence of sharp changes in welfare participation, which alleviates concerns that welfare itself is driving the effects. Finally, the results are robust to controls for time-varying measures of state welfare participation, which suggests that they are not due to other health-related public efforts for which categorical Medicaid eligibility might proxy.

The implied effects on treated infants and children are smaller than estimates from the eligibility expansions in the 1980s (Currie and Gruber 1996a; b), yet they still suggest that Medicaid had important demographic effects. I estimate that Medicaid implementation reduced aggregate nonwhite child mortality rates by 11 percent and the poverty gap in nonwhite child mortality by one third.

These results are the first to establish that the introduction of Medicaid reduced mortality. Some authors have argued that Medicaid implementation had limited health effects because poor families already received public or charity care (Roghmann et al. 1971; Klarman 1974; Matusow 1984) or because Medicaid provided low-quality services (Bernard and Feingold 1970). My results challenge these claims and show that the expansion of public insurance for poor children over and above any pre- 
Medicaid charity/public arrangements had important health benefits immediately and in the longer-term.

Because mortality is an extreme outcome, these results understate Medicaid's broader health benefits.

These findings imply that proposals to eliminate Medicaid, allow states to opt out, or cap federal reimbursements (Grannemann and Pauly 1983; Smith and Haislmeier 2009) could hurt the health of poor children even if their care is taken up by private charity to the degree that it was in the 1960s.

\section{What Do We KNow About Medicaid AND Health?}

A large literature in economics examines Medicaid's effects on insurance coverage and the use of medical care, but only a handful of quasi-experimental studies estimate its effect on health. This work consistently demonstrates that Medicaid eligibility expansions reduce mortality (the most common health outcome used in this literature), but they fail to find large effects on insurance coverage. Currie and Gruber (1996a, 1996b) find that a series of legislative increases in eligibility to pregnant women and to children during the 1980s reduced infant mortality rates by 8 percent and child mortality rates by 5 percent. ${ }^{2}$ The estimated effect of these expansions on insurance coverage, however, range from 0 (Cutler and Gruber 1996) to about 3 percentage points (Dave et al. 2008) for pregnant women, and from a slight reduction (Yazici and Kaestner 2000) to an increase of between 2.4 and 4 percentage points for children (Cutler and Gruber 1996; Shore-Sheppard 2009). Assuming that Medicaid expansions only affect the health of those who change insurance status, dividing the mortality reductions by the increase in insurance implies that Medicaid reduces mortality of those who gain insurance coverage by more than 100 percent—an impossible result. ${ }^{3}$

\footnotetext{
${ }^{2}$ Studies that examine the same eligibility expansions in individual states find much smaller effects on infant and child mortality (Piper et al. 1990; Long and Marquis 1998), although most of them suffer from methodological limitations related to poorly defined control groups (Levy and Meltzer 2004).

${ }^{3}$ Different quasi-experimental research designs and populations produce similar conclusions. Wherry and Meyer (2013) use a regression discontinuity (RD) estimator based on a provision that granted eligibility to some children born after September 30, 1983. They find that mortality rates among black children born just after the cutoff fell by about 7 percent at ages 8 to 14 , and annual internal-cause mortality rates fell by 11 percent at ages 15 to 18. Card and Shore-Sheppard (2004) use the same discontinuity and find that contemporaneous insurance coverage rose by only 10 percentage points. Sommers et al. (2012)
} 
Estimates of Medicaid's effect on health could be large relative to its effect on insurance for several reasons. The proportional treatment effects on mortality will be overstated because poorer families who actually take up Medicaid have high mortality rates and because survey data used to estimate take-up understate Medicaid coverage (Card et al. 2004; Davern et al. 2007). ${ }^{4}$ Subsequent work also documents additional channels through which the 1980s expansions may have influenced health. Families that dropped private coverage gained disposable income and consumed more (Gruber and Yelowitz 1999; Leininger et al. 2012). New Medicaid families also took up food benefits for which they were automatically eligible (Bitler and Currie 2004) which have been shown to improve infant and child health (Hoynes et al. 2011). Expansions may also have spurred investment in new technologies, which could prevent deaths among those not actually covered by Medicaid (Finkelstein 2007; Pauly and Pagán 2007). ${ }^{5}$ Finally, Dave et al. (2008) argue that estimates based on the state-by-year variation in the expansions are biased by omitted variables, although this cannot explain the large RD estimates. Thus, quasi-experimental evidence suggests that Medicaid expansions have reduced mortality, but their magnitudes preclude an interpretation of these estimates as the effect of Medicaid coverage per se.

Additional uncertainty about Medicaid's effect on health comes from the Oregon Health Insurance Experiment (OHIE), a randomized expansion of adult eligibility in 2008. Results from the first year of post-randomization data show no effects on adult mortality rates (Finkelstein et al. 2012) or on a range of clinically-measured outcomes such as blood pressure or cholesterol (Baicker et al. 2013), in contrast to quasi-experimental findings that adult Medicaid coverage reduces mortality (cf. Sommers et al. 2012). This disagreement across research designs in the short-run mortality estimates leaves open many

show that recent expansions of adult eligibility reduced mortality by 6 percent, but increased insurance coverage by only 3 percentage points.

${ }^{4}$ Appendix 4 accounts for these factors, but the implied effects of Medicaid on mortality are still larger than on insurance in several cases. Appendices available at: http://www-personal.umich.edu/ ajgb/medicaid_appendix_ajgb.pdf.

${ }^{5}$ Freedman et al. (2015) find that Medicaid eligibility expansions actually slowed the growth of neonatal intensive care units (NICU), but conclude that the marginal NICU provided no health benefits to low birth weight infants. 
important questions. ${ }^{6}$ Whether and by how much Medicaid improves health in the shorter- or longerterm remains uncertain.

\section{Public Insurance ANd Mortality Before ANd After Medicaid}

The potential for Medicaid implementation to improve health depends largely on health status and sources of care for poor families before it began. In 1950, the federal and state governments began to share some of the costs of medical care that public assistance recipients obtained from private providers. Importantly, the federal contribution was capped, which made states reluctant to broaden eligibility or cover all services. ${ }^{7}$ By 1963 only one percent of children received subsidies for health care (figure 1).

The lack of publicly-financed care was not fully offset by non-profit or private sources, a fact reflected in income differentials in insurance, utilization, and health, especially for children. Figure 1 shows that in the early 1960s, over 30 percent of children lacked health insurance (55 percent among nonwhite children and 75 percent among poor nonwhite children). Poor families especially lacked private insurance coverage: in 1959, only 8.9 percent of people with family incomes below $\$ 2,000$ had doctor visit insurance, and under a third had hospital or surgical insurance (Kovar 1960). Furthermore, only 8 percent of adults reported receiving charity care in 1960, many of whom may have mistakenly reported worker's compensation benefits (Morgan et al. 1962).

These disparities in payment sources correspond to disparities in care. Data from the 1963 Survey of Health Services Utilization and Expenditure (SHSUE) show that only 45 percent of children in the bottom third of the income distribution had seen a physician in the previous year (32 percent among nonwhite children), compared to 77 percent of children in the top third (Center for Health Administration Studies and National Opinion Research Center 1984a). ${ }^{8}$ Serious symptoms, such as 4-5

\footnotetext{
${ }^{6}$ Oregon's Medicaid expansion under the Affordable Care Act means that the OHIE can only generate short-run results.

${ }^{7} 16$ did not cover physician services, and 12 did not cover hospital services (Ways and Means Committee 1961).

${ }^{8}$ In 2011, 77 percent of children in the bottom third of the income distribution had a checkup within the previous year compared to 83 percent in the top third (Minnesota Population Center and State Health Access Data Assistance Center 2012).
} 
days of diarrhea, heart pain, or unexpected bleeding were more common for poorer children, and conditional on having less-serious symptoms such as a skin rash, a persistent cough or sore throat, or abdominal pain, children in the bottom third of the income distribution sought care much less often than those in the top third (28.5 percent versus 42 percent, standard error [s.e.] of the difference $=4.7$ ).

\section{A. A Brief History of Medicaid's Implementation}

Medicaid (P.L. 89-97) was established by the 1965 amendments to the Social Security Act (SSA), and aimed to eliminate these income-based inequalities in health and health care. ${ }^{9}$ States were required to implement Medicaid by 1970 or else lose federal reimbursements for existing medical programs. 26 states adopted Medicaid in 1966, 11 in 1967, and (most of) the rest between 1968 and 1970. ${ }^{10}$

While Medicaid was billed as an incremental change, it actually represented a major expansion in federal support for the medical care of poor families. The financial mechanism for this expansion was a move to an open-ended appropriation, which eliminated the caps on the federal contribution and increased the federal share of the cost of public medical payments from about 13 percent (Norman 1952) to between 50 and 83 percent. In return for increased federal funds, Medicaid required that states cover at least five types of care with no patient cost sharing —inpatient hospital, outpatient hospital, laboratory and $\mathrm{x}$-ray, skilled nursing home, and physician services ${ }^{11}$ —and mandated coverage for recipients of federally funded cash welfare programs (the "categorically eligible”). ${ }^{12}$

\footnotetext{
${ }^{9}$ Medicaid was was added to the SSA amendments as an "afterthought” (Ginzberg and Solow 1974; Grannemann and Pauly 1983) meant to undercut the American Medical Association's (AMA) opposition to the bill's most prominent component: Medicare. The final SSA amendments combined three proposals into Medicare Part A (compulsory hospital insurance for all elderly, the Democratic proposal), Medicare Part B (voluntary supplementary physician insurance for all elderly, the Republican proposal) and Medicaid (a federal/state funded public insurance program for the poor, the AMA's preferred program for the elderly). Assistant Secretary of the Department of Health, Education and Welfare Wilbur Cohen, remarked "It was the most brilliant legislative move I'd seen in thirty years...In effect, [Wilbur Mills (D-Arkansas)] had taken the A.M.A.'s ammunition, put it in the Republicans' gun and blown both of them off the map” (Harris 1966, pp. 40).

${ }^{10}$ Alaska did not adopt Medicaid until 1972 and Arizona did not adopt it until 1982.

${ }^{11}$ States could also choose to cover additional services, including home health care, clinic services, prescription drugs, eye care and dental care. The 1972 SSA amendments allowed states to charge co-payments for the optional services (Davis and Schoen 1978), but not for required services. Categorically eligible children were (and still are) exempt from cost sharing.

${ }^{12}$ Medicaid defined several other eligibility groups not discussed here. In particular, states could choose to cover the "medically needy"-families with incomes too high to qualify for cash public assistance, but with large medical bills that
} 


\section{B. $\quad$ Medicaid Eligibility by Age and Race}

The cash welfare recipients who gained Medicaid eligibility included the poor elderly, blind, and disabled, but the Aid to Families with Dependent Children program (AFDC) program accounted for most categorical eligibility, especially among children. 89 percent of children on Medicaid in 1976 were categorically eligible, essentially all of them through AFDC (DHEW 1966; DHEW 1976a).

AFDC-based Medicaid eligibility affected a much higher share of nonwhite children than white children. ${ }^{13}$ Figure 2 plots age-specific AFDC rates by race in 1967. Nonwhite children received AFDC more than six times as often as white children and almost four times as often as nonwhite adults. The statutory connection between AFDC receipt and Medicaid eligibility, therefore, implies that nonwhite children had by far the highest eligibility rates for the new, generous public insurance.

\section{C. $\quad$ Medicaid Use By Age and Race}

Not surprisingly, high eligibility translated into high Medicaid use. The solid line in figure 3 uses newly-entered data to plot the share of all children ages 0-19 who received medical services paid for by public insurance in the years before and after Medicaid began. ${ }^{14}$ The public insurance rate for children increased by 10 percentage points in the five years after Medicaid implementation, but only 2 percentage

pushed their net income below state-defined thresholds. The medically needy account for a small share of children on Medicaid, and I ignore this provision in the rest of the paper. For details on Medicaid eligibility see Gruber (2003).

${ }^{13}$ To measure racial differences in eligibility I entered state-level data on the race of AFDC payees and children (Mugge 1960; DHEW1963) in 1958 and 1961, and calculate race shares in 1967-1979 using microdata on AFDC recipients collected from the National Archives (DHEW 2000; 2011). I interpolate the race shares between missing years, multiply by AFDC participant counts, and divide by the relevant population to get an annual estimate of the AFDC rate by race. AFDC data contain crude measures of recipient age and race, so I construct AFDC rates for adult women and for children ages 0-19, and for a binary measure of race. Age- and race-specific welfare rates in the 1970 Census are very similar (appendix figure 2.A1). ${ }^{14}$ These data were entered from federal reports on means-tested public insurance from 1963 to 1976 (DHEW various years; see appendix 1). The data measure utilization of benefits, referring to children (ages 0-19, as defined by AFDC eligibility rules) who actually obtained medical care. More recent papers measure reported Medicaid coverage, referring to children who have signed up for but not necessarily used Medicaid. Utilization means more for health than coverage, and it incorporates the effects of provider participation in Medicaid, which would not be reflected by coverage data. Furthermore, coverage and utilization were very close for categorically eligible children. Both the 1976 Survey of Income and Education and the Office of Economic Opportunity 11-City Survey (Bailey and Goodman-Bacon 2015) show that 90 percent of families on welfare who report Medicaid coverage in a given year also report Medicaid utilization.

The new public insurance data also show that adult Medicaid use through eligibility channels other than AFDC was both high and correlated with AFDC rates (the coefficient from a regression of logs of the number of non-AFDC adults on AFDC adults in 1975 is 1.05 , s.e. $=0.04$ ). This suggests that adults are not a falsification test in this context because their Medicaid exposure was non-trivial and driven by different Medicaid or public assistance policies than for children. 
points for adults (not shown). Annual data on public insurance use by race are not available, but several sources corroborate the dramatic racial differences. The ratio of Medicaid use for nonwhite children ages 1-4 to the average child 0-19 is 3.2 in the 1976 Survey of Income and Education (US Department of Commerce 2006), and 3.7 in the 1976 National Health Interview Survey (appendix figure 2.A2).

\section{The Expected Effects of Medicaid Implementation on Mortality}

These changes may have affected a range of health outcomes, but the primary one used in this paper (and in other work on Medicaid and health) is mortality. Death is an extreme health measure, but conceptually it is an unambiguous indicator of poor health, especially for children, and unlike other health outcomes, it is well-measured and consistently available. The expected effects of Medicaid on mortality hinge on the extent to which the medical care it covered actually prevented deaths. In this regard, the groups covered the most—nonwhite children and infants—-had the greatest potential for medical-care-induced health improvements because they were relatively unhealthy in the early 1960s.

Figure 4 shows that deaths due to internal causes—a common measure of the sensitivity of mortality to medical interventions — account for nearly all infant deaths and a falling share of child deaths (60 to 50 percent). ${ }^{15}$ Nonwhite children and infants were especially at risk. Their mortality rates in 1965 were twice as high as for whites of the same age (National Center for Health Statistics [NCHS] 1965, Table 19), and they were much more likely to die of causes with "effective" treatments (Beeson 1980). For example, 35.4 percent of all nonwhite child deaths (ages 1-4) in 1965 were due to infectious diseases, compared to only 26.4 percent of white child deaths (s.e. of the difference $=0.8$ ). ${ }^{16}$

Available treatments were usually effective and often inexpensive. For example, the vast majority of pneumonia cases were bacterial, and when treated early with penicillin “approximately 95 per cent of

\footnotetext{
${ }^{15}$ The International Classification of Disease defines a set of "external” causes that include mainly transportation-related accidents, drowning, falls, poisonings, choking, homicide and suicide. All other causes are "internal".

${ }^{16}$ This primarily includes pneumonia (18 percent), meningitis (4.6 percent), and gastroenteritis (3.2 percent). Nonwhite deaths were also more likely to be due to causes so general that they reflected inadequate medical care such as "ill-defined symptoms or conditions” (5.4 percent versus 1.6 percent, s.e. of the difference $=0.3$ ).
} 
patients...recover” (Cecil et al. 1967). Many non-bacterial conditions could be managed, if not prevented or cured. Nonwhite children died from anemias twice as often as white children, but a folate supplement "suppresses or controls the disease” (Beeson 1980). Nonwhite children were also less likely to be fully vaccinated (NCHS 1976, Tables CD.I.47 and CD.I.48), and more likely to die of conditions that could be vaccinated against (1.6 versus 0.9 percent, s.e. of the difference $=0.2$ ).

Poor infants could have benefited from simple improvements in labor and delivery care. Improved monitoring (umbilical catheterization, electronic fetal monitoring, ultrasound, amniocentesis, fetal scalp blood sampling) led to earlier detection of distress "in time for the fetus to be rescued by rapid delivery" (Desmond 1998, pp. 196) and allowed more aggressive use of oxygenation after birth. ${ }^{17}$ Moderately low birth weight babies responded well to treatments such as oxygenated, temperature-controlled incubators and negative pressure ventilators ("iron lung”). Neonatal interventions improved and spread throughout the 1960s and 1970s (Budetti and McManus 1982; Cutler and Meara 1999), but these treatments had less of an impact on the lowest birth weight infants because the technology to treat respiratory distress among extremely premature infants (artificial lung surfactant) was not invented until the 1980 s.

Finally, Medicaid coverage almost certainly represented new insurance coverage at this time and, therefore, a meaningful increase in care. Figure 1 shows that the 1960s and 1970s are the only period in recent US history when changes in public coverage corresponded to similarly large reductions in the share of uninsured children (about 15 percentage points). Therefore, I expect Medicaid implementation to have the strongest effect on nonwhite infant and child mortality both because they were especially exposed to Medicaid through its link with AFDC and because they died of conditions that were treatable with the kinds of medical care funded by Medicaid.

\footnotetext{
${ }^{17}$ In the 1950s, perinatal epidemiologists showed that over-oxygenation of newborns led to blindness (retrolental fibroplasia).
} 


\section{RESEARCH DESIGN: USING INITIAL CATEGORICAL ELIGIBILITY TO IDENTIFY HETEROGENEOUS EFFECTS OF MEDICAID IMPLEMENTATION ON MORTALITY}

The categorical eligibility requirement meant that the sudden increase in public insurance eligibility

under Medicaid varied widely across states. This cross-state eligibility variation is the basis of my

research design. I identify Medicaid’s effect using a difference-in-differences model that compares state-

level health outcomes before and after Medicaid implementation in states with higher and lower categorical eligibility, measured by the state-level AFDC rate in the year of Medicaid implementation $\left(A F D C_{s}^{*}\right) .{ }^{18}$ For this approach to uncover Medicaid's health effects, $A F D C_{s}^{*}$ must correspond to increases in public insurance rates after Medicaid (relevance), and be unrelated to changes in mortality except through its statutory connection to Medicaid eligibility (excludability). This section supports these assumptions using data on AFDC-based eligibility, public insurance participation and preMedicaid state characteristics.

\section{A. Cross-State Variation in AFDC-Based Categorical Eligibility and Public Insurance Use}

In addition to higher levels of categorical eligibility, nonwhite children also experienced much greater variation in their categorical eligibility rates. White categorical eligibility rates ranged from 0.11 to 4.4 percent, but from 0.4 to 25 percent for nonwhites (appendix table 2.A1), and the variance of $A F D C_{S}^{*}$ was almost 50 times larger for nonwhites than for whites (25.4 versus 0.54). ${ }^{19}$

Cross-state differences in AFDC-based categorical eligibility correspond closely to differences in public insurance use. The dashed lines in figure 3 plot children’s public insurance utilization in highand low-eligibility states (defined by the median overall AFDC rate). The difference between high- and low-AFDC states before Medicaid implementation was very small $(0.005$, s.e. $=0.002)$, but rose to 0.05

\footnotetext{
${ }^{18}$ The calendar year of implementation is typically the year just before states' first full year with an operational Medicaid program because most programs began partway through the year and were subject to delays due to "shortages of welfare personnel to screen applications” (Tax Foundation 1968, pp. 47).

${ }^{19}$ The coefficient from a regression of nonwhite on white AFDC rates is positive (1.57) but insignificant (s.e. $=0.98$ ), with an $\mathrm{R}^{2}$ of 0.05 . Differences in the white and nonwhite ranks confirm the relatively weak association: the average state's nonwhite AFDC rank is off by 14 places from its white rank. The racial differences in AFDC variation mean that my design will have significantly more power to detect Medicaid's effect on nonwhite children than on white children, and the weak relationship between AFDC rates by race suggests that only a race-specific measure of categorical eligibility can capture this variation.
} 
(s.e. $=0.006)$ after Medicaid was fully implemented. Therefore, one identifying assumption holds: initial categorical eligibility strongly predicts post- Medicaid increases in public insurance use.

\section{B. Determinants of State-Level Categorical Eligibility}

The plausibility of the remaining identifying assumption—-that in the absence of Medicaid, mortality would have evolved similarly in higher- and lower-AFDC states—hinges on the claim that AFDC differed across states for reasons unrelated to changes in mortality in the mid-1960s. This is likely to hold for two related reasons.

First, AFDC rates were relatively long-run and stable features of states. AFDC rates vary because of factors that affect eligibility—state policies, family structures and income—and factors that affect takeup—psychic costs and institutional barriers. Cliometric studies of welfare programs show that these variables differed across states at least as far back as the 1930s, and data on AFDC rates by race in 1948, 1958 and 1961 provide direct evidence on this stability. ${ }^{20}$ The slopes from univariate regressions of $A F D C_{S}^{*}$ on AFDC rates in each prior year are positive, very precisely estimated, and not statistically distinguishable from each other. ( $p$-values from a test of the null hypothesis that they are equal are 0.82 for nonwhite rates and 0.55 for white rates; see appendix figure 2.A3.) That the variation across states in initial categorical eligibility did not emerge contemporaneously with Medicaid ameliorates concerns that states made policy choices (or recipients changed behavior) in anticipation of Medicaid's implementation. Instead, initial categorical eligibility reflects long-standing differences apparent decades beforehand.

\footnotetext{
${ }^{20}$ Moehling (2007) demonstrates that cross-state differences in family structure and the generosity of transfer programs for one-parent families existed even before the implementation of the Aid to Dependent Children program (the original name of AFDC), and persisted through the 1990s. Alston and Ferrie (1985) argue that agricultural states restricted welfare programs in the 1930s in order to maintain a "loyal" workforce. Many states and localities kept nonwhite families off the rolls by the disproportionate application of vague eligibility provisions such as "suitable home" or "substitute parent" policies that were part of pre-AFDC Mothers’ Pension programs (Bell 1965).
} 
Second, these longer-run institutional features impacted participation in ways that broke the association between policies, state characteristics and actual AFDC receipt, especially for nonwhite families. For example, since the 1940s, Texas' constitution required that increases in welfare spending, which were often necessary to comply with federal entitlement programs, be passed by popular referendum. This created major political barriers to expanding welfare programs and, not surprisingly, Texas had low white and nonwhite AFDC participation. Alternatively, Nebraska had long provided aid to unmarried mothers (Moehling 2007) so its nonwhite AFDC rate was close to the median even though its white AFDC rate was among the lowest in the country. Finally, provisions related to cohabitation, relationships, and employment were disproportionately applied to nonwhite recipients so that even a high-benefit state like Illinois had low nonwhite participation relative to its statutory generosity.

The importance of idiosyncratic institutional differences means that AFDC participation in the year of Medicaid implementation is largely unrelated to state demographic or policy characteristics, especially for nonwhite families. ${ }^{21}$ Table 1 provides evidence on the specific correlates of initial categorical eligibility by race. For a range of state characteristics $\left(y_{s t}\right)$, each row shows pre-Medicaid means and estimates of $\beta_{0}$ and $\beta_{1}$ from the following equation: $y_{s t}=\alpha+\beta_{0} A F D C_{s}^{*}+\beta_{1} A F D C_{s}^{*} \times$ $\left(y-y^{P R E}\right)+u_{s t} \cdot \beta_{0}$ tests for balance in levels between each variable in the last available year before Medicaid's passage $\left(y^{P R E}\right)$, and $\beta_{1}$ tests for balance in linear trends by $A F D C_{S}^{*} .{ }^{22}$

The results provide little evidence that $A F D C_{s}^{*}$ is correlated with levels or trends in state characteristics. Panel A uses demographic data from 1950-1965 and shows no strong correlations between initial AFDC-based Medicaid eligibility and levels or trends in mortality and birth weight

\footnotetext{
${ }^{21}$ Appendix figure 2.A4 shows that state-level eligibility estimated in the 1960 Census is positively and significantly related to receipt for white women (population-weighted OLS coefficient is 0.8 , s.e. $=0.1$ ), but not for nonwhite women $(0.3$, s.e. $=$ 0.31). This clarifies why a common strategy used to study Medicaid — the use of a simulated eligibility variable based on posted rules-would not capture the relevant variation in categorical eligibility (which is based on AFDC receipt) in the 1960s. This approach would fail to assign low levels of nonwhite Medicaid eligibility, for example, in states with generous de jure regulations but restrictive de facto welfare systems.

${ }^{22}$ The linearity restriction increases the power of the test to reject the null of common linear trends $\left(\beta_{1}=0\right)$. Appendix figure 2.B1 plots annual correlations that relax this restriction.
} 
rates. ${ }^{23}$ Comparing changes in health across values of $A F D C_{s}^{*}$ is therefore unlikely to capture preexisting trends in infant and child health or convergence in these variables.

Panel B uses 1950 and 1960 Census data to test the hypothesis that higher-AFDC states simply have more (or increasingly) disadvantaged populations. $A F D C_{S}^{*}$ bears no relationship with levels and preMedicaid trends in child poverty, family structure, adult earnings, or education. The one exception is that AFDC rates are positively related to the share of white children living without a father. Appendix figure 2.B2 shows that these socioeconomic variables did not change differentially in higher-AFDC states between 1960 and 1970, when civil rights legislation had its biggest effects on nonwhite families.

The final row of panel B and the first row of panel C test an alternative hypothesis: higher-AFDC states had more generous public programs. Data on welfare benefits from 1967 show positive but small correlations between AFDC rates and benefits, and levels and trends in aggregate government expenditures (Sylla et al. 2006) are uncorrelated with $A F D C_{S}^{*}$ (except for a positive correlation between white $A F D C_{S}^{*}$ and the level of government expenditures).

Panel C tests for balance in other health care variables that could affect child health independently of Medicaid: hospital capacity, private insurance rates. ${ }^{24}$ Despite strong growth in these variables in the mid- $20^{\text {th }}$ century, the trends are uncorrelated with initial AFDC rates. The null relationship also suggests that $A F D C_{s}^{*}$ will not capture heterogeneity in Medicaid's effect due to pre-existing insurance rates (Finkelstein and McKnight 2008) or providers' ability to serve new public insurance recipients.

In summary, table 1 supports the conclusion of cliometric research showing that the large cross-state differences in welfare-based Medicaid eligibility were inherited from long-run institutional differences

\footnotetext{
${ }^{23}$ There is a marginally significant downward trend in low birth weight for nonwhites, but it is small compared to the rate of low birth weight. A one standard deviation increase in nonwhite AFDC (5 percentage points) is associated with only a 4 percent larger reduction in low birth weight over 16 years $(-0.07 * 5 * 16 / 138.7=0.04)$. Note that the level of low and very low birth weight rates do not differ significantly by $A F D C_{S}^{*}$, suggesting that changes in the technology to treat premature infants during this time would not have disproportionately benefitted higher- versus lower-AFDC states.

${ }^{24}$ Amy Finkelstein shared the hospital data. I entered private insurance data from printed reports (Health Insurance Council 1953-1959; Health Insurance Institute 1959-1982).
} 
in the welfare system. Comparing changes in health outcomes across states with different initial

categorical eligibility rates is unlikely to confound Medicaid's effect with other factors that affect health.

\section{Data and Estimation Sample}

To measure health, I construct state-by-year infant and child mortality rates from 1950 to 1979 using Multiple-Cause of Death Files (US DHHS and NCHS 2009) and printed volumes of Vital Statistics of the United States (DHEW1953b; a; 1954-1964b; a). ${ }^{25}$ Infant mortality is measured as deaths per 1,000 live births and child mortality is measured as deaths per 100,000 children. ${ }^{26}$ I summarize these outcomes using the age-adjusted child mortality rate, which expresses infant and child rates per 100,000 and weights them together using the national age distribution in 1960.

\section{Event-Study Specification using Medicaid Implementation and $A F D C_{S}^{*}$}

Equation (1) describes a difference-in-differences (DD) model for demographic group $k$ where pre/post treatment is defined by the year of Medicaid implementation and treatment/control groups are defined by the continuous value of initial AFDC rates, $A F D C_{s}^{*}$. The estimating equation uses an eventstudy specification (Jacobson et al. 1993) that includes state-by-year-level covariates and fixed effects in $\boldsymbol{x}_{\boldsymbol{s} t}^{\prime}$, and interactions between $A F D C_{s}^{*}$ and dummy variables that measure the time relative to Medicaid implementation, $1\left\{t-t_{s}^{*}=y\right\}$ (i.e., "event-time”): ${ }^{27}$

$$
\ln \left(A S M R_{s t}^{k}\right)=\boldsymbol{x}_{s t}^{\prime} \boldsymbol{\beta}_{\boldsymbol{k}}+A F D C_{s}^{*}\left[\sum_{y=-17}^{-2} \pi_{y}^{k} 1\left\{t-t_{s}^{*}=y\right\}+\sum_{y=0}^{10} \gamma_{y}^{k} 1\left\{t-t_{s}^{*}=y\right\}\right]+e_{s t}^{k}
$$

\footnotetext{
${ }^{25}$ The exception is 1972, which contains a 50 percent sample, and 1981 and 1982 which contain a 50 percent sample for some states. In 1981 and 1982, I use Mortality Detail files, and in 1972, the mortality data are based on the reduced sample. ${ }^{26}$ Denominators for the child rates were constructed by linearly interpolating population between the 1950 and 1960 censuses (Haines and ICPSR 2005) and the 1969 to 1988 Surveillance Epidemiology and End Results (SEER 2009) data. Denominators for the infant rates were calculated from Vital Statistics Natality Microdata from 1968-1979 (US DHHS and NCHS 2002) and entered state totals from Vital Statistics reports from 1950-1967. I end the sample in 1979 because the 1980s eligibility expansions largely eliminated the state differences that drive my results. Appendix figure 2.C1 shows that the correlation between $A F D C_{s}^{*}$ and Medicaid eligibility falls during the 1980s and that the mortality results attenuate. ${ }^{27}$ I use AFDC rates for women because it is the appropriate measure of eligibility for the infant (especially neonatal) mortality regressions. The results for non-infant children are unchanged when I use child AFDC rates (appendix figure 2.C5).
} 
My preferred specification includes per-capita income, per-capita hospital beds, state fixed effects and nonparametric controls for two kinds of time-varying unobservables: region-by-year fixed effects, and a separate set of year fixed effects for each Medicaid timing group.

Conditional on region-by-year fixed effects, the estimates rely on mortality comparisons across $A F D C_{s}^{*}$ within each region. I modify the four Census regions to match the definition of the South in Chay et al. (2009). ${ }^{28}$ This controls for the strong convergence in mortality between the South and the rest of the U.S. due to hospital desegregation (Almond et al. 2006), region-level trends in school quality (Stephens and Yang 2013), and regional differences in private insurance coverage (Finkelstein and McKnight 2008).

Medicaid-timing-by-year fixed effects eliminate comparisons between states that adopted Medicaid earlier or later. A DD model based only on the differential timing of Medicaid adoption is identified (Decker and Gruber 1993; Strumpf 2011), however in my context, differential mortality trends in earlier and later Medicaid states violate the identifying assumption of this “timing-only" estimator (see appendix 3). Policymakers at the time reported putting off Medicaid implementation because of fiscal concerns (ACIR 1968), and Finkelstein (2007) concludes that, with respect to hospital capacity, "the timing of state implementation of Medicaid was not random.” The Medicaid-timing-by-year fixed effects ensure that estimates of equation (1) rely only on comparisons between AFDC groups rather than between earlier and later Medicaid states.

The coefficients of interest, $\pi_{y}^{k}$ and $\gamma_{y}^{k}$, measure the (covariate-adjusted) relationship between log mortality and initial AFDC rates in the 16 years leading up to Medicaid's introduction and the nine years after. The dummy for the year before Medicaid is omitted, which normalizes the estimates of $\pi_{y}^{k}$ and

\footnotetext{
${ }^{28}$ The South includes Alabama, Arkansas, Florida, Georgia, Louisiana, Mississippi, North Carolina, South Carolina, Tennessee and Virginia, and "border" states include Delaware, Kentucky, Maryland, Texas, and West Virginia, plus Oklahoma and Washington D.C., which are not categorized in Chay et al. (2009).
} 
$\gamma_{y}^{k}$ to zero in that event-year. ${ }^{29}$ The $\pi_{y}^{k}$ are falsification tests that capture the relationship between initial categorical eligibility and outcomes before Medicaid existed. Their pattern and statistical significance are a direct test of the common trends assumption. The $\gamma_{y}^{k}$ are intention-to-treat (ITT) effects of an additional percentage point of initial Medicaid eligibility on aggregate mortality. This specification identifies heterogeneity in Medicaid’s effect. The estimates will equal zero if Medicaid affected mortality equally across states. Moreover, they will understate Medicaid’s total effect on mortality because they “difference out” any portion of the effect that is equal across states. For example, if Medicaid led to investments in hospital technologies, as was the case for Medicare (Finkelstein 2007), then mortality effects arising from investment that is common to higher- and lower-AFDC states will not be captured by this empirical strategy.

I also present the coefficients from a "grouped” event-study specification that combines the eventtime dummies into four bins ([-16,-12], [-11,-8],[-7,-2], [0], [1,4], [5,9]) and a difference-in-difference (DD) specification that estimates one treatment effect for event-years [1,9]. I cluster standard errors at the state-level to allow for arbitrary serial correlation within states.

\section{ESTIMATES OF MEDICAID’s INTENTION-TO-TREAT EFFECT ON MORTALITY RATES}

The primary mechanism through which Medicaid implementation should affect mortality is by increasing the utilization of (publicly-financed) health services. Figure 5 plots estimates of equation (1) using child public insurance rates from 1963-1976 as the dependent variable (covering event-years -3 through 6). Before Medicaid, public insurance use is uncorrelated with $A F D C_{s}^{*}$ (the $p$-value from a joint significance test of the -3 and -2 coefficients is 0.70). After Medicaid implementation, states with higher initial eligibility have much larger increases in public insurance use than lower-eligibility states. For each percentage point of $A F D C_{s}^{*}$, post-Medicaid public insurance use is 4 percentage points higher (s.e.

\footnotetext{
${ }^{29}$ Event-time dummies that are more than 16 years before or nine years after Medicaid implementation are grouped because not all states are observed at these event-years.
} 
$=1.01$ ). These results show that, even conditional on covariates, AFDC-based eligibility is strongly associated with increases in public insurance after Medicaid. ${ }^{30}$

\section{A. Results for Age-Adjusted Child Mortality by Race}

Figure 6 presents event-study estimates of Medicaid's ITT effect on a summary mortality measure: log age-adjusted mortality for children ages $0-14 .{ }^{31}$ The small pre-Medicaid estimates for nonwhite children (panel A) strongly support the AFDC-based research design in equation (1). In the 16 years before Medicaid, higher- and lower-nonwhite eligibility states had nearly identical mortality changes. Concerns about differential mortality trends between AFDC groups are not borne out in these results.

Medicaid's ITT effects on nonwhite mortality are large, negative, and very precise. The estimates fall sharply in the year of Medicaid implementation (time zero on the $x$-axis), continue falling for two years. This matches the pattern in the first-stage estimates and reflects the fact that Medicaid programs were only partially implemented in the first calendar year. The estimates remain negative for nine years, and the DD estimate shows that for every percentage point difference in initial AFDC rates, nonwhite child mortality fell by 1.4 percent (s.e. $=0.34$ ).

Consistent with the large differences in AFDC variation by race, panel B shows noisy but suggestive estimates for white child mortality rates. The pre-trend in mortality is relatively flat starting about 10 years before Medicaid and white mortality fell after Medicaid in higher-AFDC states (the event-study point estimates are greater than zero mainly because there is a jump down in the omitted period, -1$)$. The DD coefficient is imprecise, but very similar to the nonwhite estimate $(-1.50$, s.e. $=1.90)$ and not statistically distinguishable in a pooled model (difference $=-0.09$, s.e. $=1.9$ ). The results suggest that Medicaid affected mortality similarly for white and nonwhite children, but the AFDC-based design only

\footnotetext{
${ }^{30}$ Appendix figure 2.A5 shows that per-recipient expenditures did not change differently after Medicaid in higher- and lowerAFDC states. There is also no cross-sectional relationship between $A F D C_{s}^{*}$ and per-recipient expenditures after Medicaid (coef. $=-2.7$, s.e $=14$ ). This suggests that the size of the categorically-eligible population, while strongly related to Medicaid use, is not related to the value of services received by the average child on Medicaid.

${ }^{31}$ The choice of ages follows Currie and Gruber (1996a).
} 
has sufficient power to detect nonwhite effects. The rest of the results focus on nonwhite outcomes, but estimates for whites are in appendix 2.

Table 3 shows that the nonwhite treatment effects are robust across a range of specifications. ${ }^{32}$ Estimates from the simplest possible specification (column 1), which is equivalent to comparing the slope between mortality and $A F D C_{s}^{*}$ across event-times, show a significant effect of Medicaid that are about half as large as in the full specification from figure 6 (column 2). Neither omitting the population weights (column 3) nor including state-specific linear time trends (column 4) changes the results. ${ }^{33}$ Panel B also shows the $p$-value from a test of the DD restrictions in the grouped event-study model: the pre-Medicaid coefficients equals zero and the post-Medicaid coefficients (except year 0) are equal. These restrictions are not rejected for any model.

The final two columns present alternative estimates that support the AFDC-based research design. Column 5 stacks child mortality rates by race, includes state-by-year fixed effects and presents coefficients on the triple interaction between Medicaid timing, $A F D C_{s}^{*}$, and a nonwhite dummy. The results are slightly larger in this more demanding specification. Column 7 presents two-stage least squares estimates that instrument for the $A F D C_{s}^{*}$ interactions using similar variables constructed from 1958 AFDC data. This addresses the concern that initial AFDC participation captures differences in state trends or unobserved policy changes that predict mortality reductions. The evidence section II implies that this should not change the results, and the results in column 7 bear this out. Table 3 , therefore, supports the AFDC-based identification strategy and strengthens the conclusion that Medicaid reduced nonwhite child mortality.

\footnotetext{
${ }^{32}$ The analysis includes 45 states, which is typically enough to avoid the bias that arises from standard error estimation using a small number of clusters (Bertrand et al. 2004; Cameron et al. 2008). Panel B of table 3 also shows two-sided $p$-values from 1,000 draws of a wild-cluster bootstrap percentile-t procedure, as suggested by (Cameron et al. 2008).

${ }^{33}$ A Hausman test cannot reject the null hypothesis of equality between the weighted and unweighted estimates for either panel A ( $p$-value $=0.50)$ or panel B ( $p$-value $=0.90)$ (Deaton 1997). The motivation for a test comparing weighted and unweighted estimates is to detect unmodeled heterogeneity or other forms of misspecification, in which case the two estimators may disagree (DuMouchel and Duncan 1983; Solon et al. 2015). My results are invariant to weighting, so I present the more precise weighted results.
} 


\section{B. Results for Nonwhite Infant Mortality by Age}

The age-adjusted mortality rates discussed above are largely driven by infants, a group for which we have detailed information on deaths (by precise age), other measures of health (birth weight), and rough measures of medical care (site of births). Together these data suggest that Medicaid reduced infant mortality immediately after birth via labor and delivery care rather than improvements in underlying fetal health or in the incidence of infectious disease in later infancy.

Panel A of figure 7 plots event-study estimates for infant mortality by age at death, and shows that Medicaid's effects are strongest just after birth. The pre-Medicaid point estimates for first-day mortality are small and insignificant (a linear pre-trend is -0.027 , s.e. $=0.042$ ), and fall sharply after Medicaid. The DD estimate in table 4 shows that for each percentage point of initial eligibility, first-day mortality is 1.5 percent lower after Medicaid (s.e. $=0.47$, column 1 ). The effects in the rest of the neonatal period (days 2-28) are similar (DD estimate is -1.61 ) but noisier (s.e. $=0.86$ ) because only 30 percent of neonatal deaths occur after the first day. The estimates for post-neonatal mortality (PNMR), on the other hand, show a downward pre-trend (linear pre-trend is -0.13 , s.e. $=0.08$ ) and are not consistent with an effect of Medicaid. While the DD estimate in column 4 of table 4 is very similar to the neonatal estimate, the DD restrictions are rejected suggesting that this is a not a reliable specification for PNMR. Furthermore, this result is sensitive to small sample changes (it falls to -0.89 [s.e. $=0.72$ ] if Texas is dropped) and different AFDC measurements (the effect is -2.6 [s.e. = 4.2] using a binary measure of AFDC that cuts states at the median). ${ }^{34}$ The row labeled “contribution to IMR effect” combines the proportional reductions by age group with baseline mortality rates and shows that the first day accounts for half of the overall infant mortality coefficient (very close to its share of deaths, 17.8/37.6 $=0.47$ ).

Figure 8 uses data on the hour and day of death (available beginning in 1959), to decompose the neonatal effects further. Each point is a DD estimate of the cumulative mortality rate through each hour

\footnotetext{
${ }^{34}$ The neonatal results are robust to dropping Texas $(-1.0$, s.e. $=0.37)$, and using a binary AFDC measure $(-7.1$, s.e. $=3.2)$.
} 
or day (so the rightmost point is comparable to the neonatal effect from table 4). The results show that nearly all of Medicaid's effect manifests immediately after birth, is biggest after 3 hours (-1.9 percent for each percentage point of initial eligibility, s.e. $=0.51$ ), and rebounds slightly during the first day. The attenuation most likely reflects negative selection into the group of surviving infants: the weakest babies saved in the first hours do not survive the first day. Appendix figure 2.F1 shows that 80 percent of the first-day effect (and 60 percent of the neonatal effect) comes in the first 6 hours.

Several features of the infant results by age help rule out a closely related explanation for nonwhite infant mortality reductions in the 1960s: hospital desegregation. First, the desegregation of southern hospitals after 1965 mainly affected post-neonatal infectious disease deaths. The importance of deaths in the first day and first few hours mean that Medicaid must have improved infant health through distinct channels because no infants could have contracted such illnesses so quickly. Second, most southern states implemented Medicaid in 1970, while desegregation began in 1965. Figure 7 does not show a pretrend in first-day or neonatal mortality that points towards desegregation as an explanation. Third, the model includes separate year fixed effects for Southern and border states, where desegregation was concentrated, and the estimates are unchanged by dropping these states (appendix table 2.D1). Fourth, the effects on first-day and neonatal mortality are robust to including post-neonatal mortality rates as a proxy for the timing, incidence and health effects of hospital desegregation (as well as other determinants of infant survival). The DD effects on first-day mortality $(-1.42$, s.e. $=0.46)$ and neonatal mortality $(-1.25$, s.e. $=0.35)$ change little after conditioning on PNMR directly (appendix table 2.D6).

\section{Results for Nonwhite Health at Birth}

Reductions in immediate infant deaths could be due to improvements in health at birth or reductions in mortality rates conditional on fitness. The evidence suggests that Medicaid worked through the latter channel and did not have meaningful effects on health at birth. 
The first three columns of table 5 show small and, in most cases, imprecise effects of Medicaid on three measures of health at birth: the log of very low and low birth weight rates, and the male/female sex ratio at birth. ${ }^{35}$ The DD estimate for very low birth weight is negative and relatively precise $(p$-value $=$ 0.12), but the DD restrictions are strongly rejected, the point estimates are slightly negative in the years prior to Medicaid (panel A), and the estimates are sensitive to including the oldest data points. ${ }^{36}$ Both the grouped event-study and DD point estimates for low birth weight and the sex ratio are small and insignificant. These results differ from evidence based on the timing of Medicaid implementation (Decker and Gruber 1993) and, to some extent, expanded Medicaid eligibility for poor mothers (Currie and Gruber 1996b). ${ }^{37}$ Nevertheless, they are consistent with the skepticism expressed by some perinatal epidemiologists about the effect of prenatal care on birth weight (Fiscella 1995; Alexander and Kotelchuck 2001), with evidence from the introduction of national health insurance in Canada (Hanratty 1996), and with evidence from Medicaid hospital payment reforms in California (Aizer et al. 2004). ${ }^{38}$ Strong mortality reductions without corresponding improvements in fitness at birth imply that Medicaid improved survival conditional on health at birth. Panel $\mathrm{C}$ of table 4 tests this by adding the birth weight variables to the infant mortality regressions. (Birth-weight-specific mortality rates require linked birth and death records, which are not available during this period.) The mortality effects change

\footnotetext{
${ }^{35}$ Male fetuses are more vulnerable to in utero conditions, so the share of boys carried to term can be interpreted as a measure of average fetal health (Sanders and Stoecker 2015). Birth weight is taken from natality microdata for 1968-1979, and from printed volumes from 1950-1967. About 0.5 percent of births are missing weight data and table 4 assumes they are missing at random. Changes in the share missing (per 1,000 births) are unrelated to $A F D C_{s}^{*}$ (coefficient $=0.23$, s.e. $=0.39$ ).

${ }^{36}$ The VLBW estimate is halved in a sample starting in $1959(-0.42$, s.e. $=0.37)$, but infant mortality results are unaffected (1.4 , s.e. $=0.32)$.

${ }^{37}$ Decker and Gruber (1993) identify the effect of Medicaid implementation by using the timing of state adoption, which is discussed more fully in appendix 3. Currie and Gruber (1996b) document a role both for reductions in low birth weight and acute care at birth, and argue that care at birth represented a relatively high cost way to save infant lives.

${ }^{38}$ In economics, Evans and Lien (2005) use a 1992 bus strike in Pittsburgh as an instrument for prenatal care visits and are unable to detect effects on birth weight or infant health. They demonstrate reductions in maternal smoking, but this advice would certainly have been less common in the 1960s, only a few years after the Surgeon General's report on smoking in pregnancy was released, and also possibly less common among providers serving poor women (Aizer and Stroud 2010).
} 
very little, which lends further support to the claim that Medicaid increased survival conditional on health at birth. ${ }^{39}$

\section{Results for Nonwhite Labor and Delivery Care}

The main channel through which Medicaid could have reduced such short run infant mortality rates without improving fetal health is through improvements in acute care at birth. Consistent with this explanation, column 5 of table 4 shows that Medicaid reduced an outcome that is highly correlated with hospital care: maternal mortality. ${ }^{40}$ Each percentage point of initial eligibility reduces maternal mortality by 0.16 deaths per 100,000 women $($ s.e. $=0.10$ ), or about 2 percent of the baseline level. Maternal mortality is quite noisy in the early 60s, and the results are much more precise in alternative specifications: controlling for event-time $-7(-0.22$, s.e. $=0.10)$, using a binary AFDC measure $(-1.74$, s.e. $=0.66)$, or estimating a linear probability model for any maternal deaths $(-0.008$, s.e. $=0.004) .{ }^{41}$ Reductions in maternal deaths strongly suggest that the mechanisms for infant survival have to do with hospital care that also benefitted mothers (cf. Kutinova and Conway 2008).

One data source allows a unique and direct test of whether Medicaid increased hospital care at birth.

The 1964-1969 and 1972 National Natality Surveys (or the National Natality Followback Survey, NNFBS) contain a sample of 3,821 nonwhite births with socioeconomic variables and information about infant health and the site of births. ${ }^{42}$ I use data on birth order and income to create more detailed

\footnotetext{
${ }^{39}$ The first-day and neonatal effects are also robust to dropping California, New York, and Washington, the states in the estimation sample that legalized abortion before the 1973 Roe v. Wade decision (appendix table 2.D1). This addresses the possibility of differential selection induced by legalized abortion.

${ }^{40}$ At least two thirds of all maternal deaths in 1965 related to acute events such as abortion (spontaneous or induced; 19 percent of maternal deaths), or complications during and after delivery (33 and 16 percent). Many causes of earlier death could have been prevented in hospitals, such as severe pre-eclampsia. I use the level rather than log of age-adjusted maternal mortality (using the 1960 national age distribution of women 15-54) since many cells have no maternal deaths.

${ }^{41}$ These changes address a spike in maternal mortality in Alabama (a relatively high AFDC state) in 1963 (event-time -7).

${ }^{42}$ The NNFBS sampling frame is "legitimate births", meaning that the mothers were married at the time of the birth. While AFDC would have primarily covered illegitimate births, there is still some overlap between the NNFBS sample and categorically eligible mothers. Two thirds of AFDC mothers in the 1967 Characteristics Survey had been married at some point, and about 13 percent of nonwhite respondents in the 1967-1969 NNFBS report receiving welfare income (compared to 11 percent of nonwhite women overall). More than a third of black Medicaid births in California in 1967-1968 were
} 
comparison groups than in analyses of aggregate data. In 1967, 18 states provided AFDC (and

Medicaid) to mothers pregnant with their first child. Therefore, comparing results for covered births (higher-order births and first births in states that provided AFDC to first-time pregnant mothers) and non-covered births to richer and poorer mothers provides an additional test of whether the effects are due to Medicaid

Table 6 presents the results from linear probability models that include the same fixed effects included in equation (1) as well as individual-level covariates: mother's age dummies, dummies for plural and first births, a dummy for the baby's sex, and separate sets of family income dummies for each year. The coefficients of interest are triple interactions between a post-Medicaid dummy, $A F D C_{S}^{*}$, and dummies for groups defined by poverty status and the possibility of perinatal Medicaid coverage.

Column 1 of table 6 shows that poor nonwhite mothers whose births were covered by Medicaid were more likely to give birth in an institution (almost always a hospital). Each percentage point of initial eligibility is associated with 0.62 percentage point increase in the hospital birth probability (s.e. $=0.32$, baseline hospital probability is 88 percent), but births not covered by Medicaid were unaffected. ${ }^{43}$ Columns 2 and 3 reestablish that Medicaid did not affect health at birth: even for poor nonwhite women whose births could have been covered by Medicaid, initial eligibility is uncorrelated with changes in the probability of low birth weight or prematurity.

No nationally representative data exist to quantify two other hospital-based channels through which Medicaid may affect infant survival: improved care at a given hospital (Currie and Gruber 2001) and sorting of newly insured mothers into better hospitals (Aizer et al. 2004). Data from California, legitimate (California Public Health Service 1973). Furthermore, mothers could have misreported marital status to welfare authorities or on the child's birth certificate.

43 This effect also appears to some extent in aggregate data on hospital births in the South. Appendix figure 2.E3 plots eventstudy estimates of Medicaid's effect on the racial gap in hospital births. The estimates show a clear upward trend break in the South, where most of the racial convergence in hospital births occurred. The DD estimate using $A F D C_{s}^{*}$ is quite noisy $(0.25$, s.e. $=0.39)$, but one that uses a binary specification is more precise $(0.046$, s.e. $=0.029$, bootstrap $p$-value $=0.14)$. The effect using all states is much smaller, suggesting that the movement of births into hospitals cannot explain the entire neonatal mortality effect, which is robust to dropping the South (see appendix table 2.D1). 
however, support an important role for hospital switching. Between 1965 and 1970 the share of black births in public county hospitals fell from 51 to 18 percent (table 9), perinatal mortality rates—primarily those in non-county facilities—-fell by 16 percent (table 2), while the birth weight rate distribution remained constant (California Public Health Service 1973). The results are very similar to Aizer et al. (2004) who find that moving Medicaid mothers into better hospitals reduced neonatal mortality and prematurity among black Medicaid recipients, but had no effect on the probability of low birth weight.

The estimated effects of Medicaid on infants-reductions in immediate infant and maternal mortality rates, no changes in health at birth, and increases in hospital care-match the conclusions from perinatal epidemiological research which finds that changes in the distribution of fitness at birth account for only a small share of neonatal mortality declines since 1950 (Lee et al. 1980; Williams and Chen 1982; David and Siegel 1983; Collins and Thomasson 2004; Cutler and Meara 2004). Therefore, Medicaid implementation can help explain both the aggregate changes in race-specific neonatal mortality and the important contribution of acute care and survival conditional on health at birth.

\section{E. Results for Nonwhite Child Mortality by Age and Cause}

While infants accounted for most deaths under age 14, the vast majority of child Medicaid recipients were older than 1. Panel B of figure 7 shows that Medicaid's effects on this group are concentrated among the youngest children. The pre-Medicaid coefficients for mortality at ages 1-4 are small and insignificant and there is a sharp reduction immediately after Medicaid. The DD estimate (column 1, table 7) shows that each percentage point of initial eligibility is associated with a -2.23 percent reduction in younger child mortality (s.e. $=0.55$ ). Columns 2 and 3 suggest that Medicaid's effects decline with age. The DD estimate for ages 5-9 is negative, but less than a quarter of the effect for younger children $(-0.51$, s.e. $=0.40)$, and the result for ages $10-14$ is very close to zero $(-0.13$, s.e. $=0.56)$. 
Columns 4 and 5 bear out another prediction from section II.D: that internal-cause mortality responds more to Medicaid than external cause mortality. Nearly all of Medicaid's effect on child mortality comes from reductions in internal-cause deaths (column 3). The DD effect on internal-cause mortality is a 1.88 percent reduction and is very precisely estimated (s.e. $=0.41$ ), while the proportional effect on external-cause mortality is smaller $(-0.96$, s.e. $=0.55)$ and is relative to a lower base $(39.2$ versus 48 deaths per 100,000). About 70 percent of the combined effect across columns 4 and 5 comes from internal causes $(-1.88 * 48 /(-1.88 * 48-0.96 * 39.2)=0.70)$. The $p$-value from a test of the equality of the internal and external cause estimates is 0.12 .

The final two columns suggest that the internal-cause effects arise mainly through Medicaid's effect on infectious disease mortality. Columns 5 and 6 split internal-cause deaths into those that are treatable and untreatable according to Beeson (1980). ${ }^{44}$ Three quarters of internal causes are treatable by this measure, most of which are infectious diseases. The treatment effect on treatable cause mortality is -2.16 percent $($ s.e. $=0.51)$, compared to only -1.09 percent $($ s.e. $=0.80)$ for untreatable causes. ${ }^{45}$

Fatal infectious diseases at this time were most often treated with antibiotics or other drugs when detected early enough, so in order to achieve the mortality reductions in table 6 , Medicaid would have had to provide such care. Columns 2 through 5 of table 2 provide additional first-stage DD estimates of Medicaid's effect on the utilization of four specific services: hospital admission, physician visits, prescription drugs, and dental services. The pattern of increases in public health care use correspond to the types of care that were effective in reducing the types of mortality that actually decreased for young children after Medicaid. One percentage point of initial eligibility is associated with more than a 2

\footnotetext{
${ }^{44}$ Beeson categorizes a range of conditions according to a ten-point scale of treatability in 1975. I assume all internal-cause deaths are treatable unless their 1975 treatment falls in the bottom 6 categories of treatability. Treatable conditions generally meet one of the following criteria: treatment suppresses or controls disease, but must be maintained indefinitely; treatment of manifestations substantially improved and/or diversified; effective treatment in most circumstances; effect preventive treatment. Untreatable conditions include all cancers except leukemia; degenerative conditions of the central nervous system such as multiple sclerosis; certain chronic conditions such as asthma or rheumatic fever; infectious conditions such as coccidiosis ("valley fever"); and some rare parasitic diseases.

${ }^{45}$ Appendix figures 2.C7 and 2.C8 present event-study estimates associated with columns 4-7 of table 7.
} 
percent increase in children's use of (publicly financed) doctor visits and prescription drugs, but smaller increases in hospital admissions and dental visits (largely because baseline utilization is low).

\section{Evidence On Potential Threats to Identification}

The results presented above are consistent with a causal effect of Medicaid implementation on mortality, particularly because they clearly show that mortality in higher- and lower-AFDC did not trend differently for 16 pre-Medicaid years. The remaining threats to identification, therefore, are variables that affect groups covered by Medicaid, that differ by $A F D C_{s}^{*}$, and that change sharply at the same time as Medicaid implementation (but are not caused by it).

\section{A. Direct Evidence on Other Federal Spending}

If initial AFDC-based Medicaid eligibility signals states’ willingness to adopt other social policy reforms of the 1960s, then the estimates of $\gamma_{y}^{k}$ could capture the mortality-reducing effects of related War on Poverty programs. To test this hypothesis, I estimate versions of equation (1) using recently collected measures of per-capita expenditures or participation rates for four major programs that could have also affected child mortality. ${ }^{46}$ Panel A of figure 8 shows the results for per-capita federal expenditures for Community Health Centers (CHC), other health programs funded by the Community Action Program (CAP), and Head Start (per 1,000 children ages 1-9). For comparison, I also include estimates for public insurance expenditures on children per 1,000 children ages 1-19 (the expenditures version of the first-stage results in figure 5). Panel B shows the results of similar regressions for participation rates in the Food Stamp Program, and for the white and non-white AFDC rates used to calculate $A F D C_{s}^{*}$ (alongside the public insurance estimates from figure 5).

Changes in per-capita expenditures on other health-related programs are both uncorrelated with Medicaid implementation and small, especially relative to the large effects on public insurance spending

\footnotetext{
${ }^{46}$ For the expenditures and participation rates that are not measured by race, $A F D C_{s}^{*}$ is based on overall AFDC rate (as in the first-stage results) rather than race-specific AFDC rates.
} 
and utilization. This is especially reassuring for two programs that have been shown to affect infant and child health: Head Start (Ludwig and Miller 2007) and Food Stamps (Almond et al. 2011). ${ }^{47}$ The eventstudy results for both Head Start spending (panel A) and Food Stamp participation (panel B) are indistinguishable from zero, and do not change sharply in the year of Medicaid implementation. It is unlikely that the expansion of related federal programs explains the mortality results in section IV.

Panel B also shows that changes in AFDC rates themselves cannot explain the mortality results. Neither white nor nonwhite AFDC show strong changes after Medicaid correlated with $A F D C_{s}^{*}$ (the white DD estimate is 0.10 , s.e. $=0.38$, and the nonwhite DD estimate is 0.07 , s.e. $=0.21$ ). Furthermore, evidence on the relationship between welfare receipt and health is mixed (Currie and Cole 1993; Bitler et al. 2005; Leonard and Mas 2008), so even if AFDC rates were correlated with Medicaid timing, it is not clear that this could generate large mortality reductions. ${ }^{48}$

\section{B. Indirect Evidence Adding Controls for State-Level Welfare Programs}

The results in figure 8 show that several observable federal programs cannot account for the Medicaid estimates. Another approach to rule out alternative explanations is to add other measures of state welfare programs to equation (1). If the results are spurious, then other transfer program measures should be highly correlated with omitted variables that account for the post-Medicaid mortality reductions, and the main treatment effects should fall toward zero.

The first approach is a falsification test that asks whether another measure of state welfare rates can account for the post-Medicaid mortality changes for nonwhite children. I add interactions of the eventtime variables with initial white AFDC rates to the regressions for nonwhite mortality rates. If higher-

\footnotetext{
${ }^{47}$ The DD estimate for community health center spending is statistically significant, but it is more than an order of magnitude smaller than the public insurance estimate. This also overstates the per-capita CHC spending for children because is an average that includes much higher expenditures for older users. Furthermore, Bailey and Goodman-Bacon (2015) find no evidence that CHCs affect child or infant mortality, which means that even a large change in funding would not be a plausible explanation for the mortality reductions in section IV.

${ }^{48}$ Appendix figure 2.B4 uses data from the 1970 Census to show that net cross-state population flows between 1965 and 1970 are uncorrelated with $A F D C_{s}^{*}$. This is consistent with the fact that that per-recipient benefits did not increase in higherAFDC states, and suggests that selective migration cannot explain the mortality results.
} 
AFDC states simply increased the availability of other effective (and omitted) services, then the white and nonwhite treatment variables would contain essentially the same information about omitted variables that drive the nonwhite mortality rates. The results in panel A of table 8 show that the main treatment effects are unchanged when white-AFDC interactions are included, and that the relationship between changes in nonwhite mortality and white eligibility is small.

The history of AFDC, however, suggests that white and nonwhite participation represents different factors (section III.B), and that omitted determinants of mortality may be specifically correlated with nonwhite AFDC. Because the identification strategy is based on nonwhite AFDC rates at one point in (event) time, I can address this concern by including the actual state-by-year nonwhite AFDC rate as an additional covariate in equation (1). If changes in nonwhite welfare rates stand in for underlying shifts in factors such as discrimination, industrial structure or safety-net policy that also affect mortality, then the observed nonwhite AFDC rate will capture all the relevant variation in mortality during this time period, and eliminate the estimated Medicaid effects. Panel B of table 8 presents DD estimates that include the state-by-year nonwhite AFDC rate and its interaction with a post-1966 dummy, to allow for possible structural changes in AFDC participation during the 1960s (Moffitt 1987). The treatment effects are only slightly reduced by these flexible controls and remain statistically significant, suggesting that the changes in nonwhite AFDC during the 1960s cannot account for the strong correlation between initial categorical eligibility and the timing of Medicaid implementation.

\section{Discussion: INTERPRETING THE MORTALITY EFFECTS OF MEDICAID IMPLEMENTATION}

The preceding evidence suggests that Medicaid implementation succeeded in increasing public insurance coverage and reducing mortality among children. But given that previous studies have estimated effects for similar populations, how do these results affect our understanding of how public insurance influences mortality generally? 


\section{A. The Average Treatment Effect of Medicaid on the Mortality of Treated Children}

Section I argued that existing estimates of Medicaid's effects on infant and child mortality are too large to be attributed to new insurance coverage alone. This conclusion is based on the proportional average treatment effects on the treated (ATET) of Medicaid coverage. This parameter is comparable across studies because it is not tied to the scale of a particular policy change or to the baseline mortality rate of different target populations. It is also a useful check on the plausibility of attributing a given result entirely to changes in insurance because the proportional ATET cannot be below -100 percent, as this implies that Medicaid reduces mortality by more than its baseline level.

To calculate the ATET, I first divide the DD mortality estimate for nonwhite children by the appropriate first-stage estimate for insurance coverage. This assumes that no categorically eligible Medicaid recipients dropped private insurance coverage. This type of crowd-out is not a concern in the 1960s when private insurance coverage among AFDC recipients, whose full-time employment rate was below 5 percent (DHEW 1963), was certainly close to zero. ${ }^{49}$ I also adjust for the higher mortality rates of Medicaid recipients using survey data on mortality by income (see appendix 4).

Figure 10 plots estimates of the ATET from this paper and from the three most closely related Medicaid papers (Currie and Gruber 1996a; b; Wherry and Meyer 2013). ${ }^{50}$ I construct confidence intervals using a parametric bootstrap procedure (Efron and Tibshirani 1993) that uses 10,000 draws of the reduced-form and first-stage estimates from normal distributions with means and standard deviations equal to the point estimates and standard errors, and calculates the ATET for each draw (see appendix

\footnotetext{
${ }^{49}$ This is also borne out in figure 1, which shows that the magnitude of public coverage gains and reductions in uninsurance correspond closely in the 1960s and 1970s (but not since), reflecting the limited scope for crowd-out. Loewenstein (1971) finds that 8 percent of categorically eligible Medicaid families in 1968 had any health insurance, and only 3 percent had anything other than hospital or surgical insurance. Among all poor families in states that had not yet adopted Medicaid (mostly in the south plus New Jersey and Indiana) only 6 percent had doctor visit insurance.

${ }^{50}$ For more recent papers, I use first-stage estimates for any health insurance rather than Medicaid coverage and adjust them by a factor of 0.85 to account for underreporting of Medicaid in survey data (Card et al. 2004; Davern et al. 2007).
} 
4). ${ }^{51}$ This method allows me to calculate confidence intervals for other papers without resampling from their data. I calculate confidence intervals using a modified percentile method (Johnston and DiNardo 1997), because the distribution of the ATET is not symmetric. This highlights an advantage of the parametric bootstrap over an approach based on a linear approximation (delta method) which would yield a symmetric and misleading confidence interval.

The ATET estimates reaffirm that Medicaid significantly reduced nonwhite infant and child mortality rates, and the magnitudes are smaller than -100 percent, satisfying a necessary condition for attributing effects to Medicaid's insurance coverage alone. The ATETs imply a 20 percent mortality reduction for nonwhite children under 14, and a 30 percent reduction for younger nonwhite children (ages 1-4) and nonwhite neonates. The confidence intervals never include zero or -100 percent. $^{52}$

These estimates imply large individual health effects compared to other interventions. A 30 percent reduction in neonatal mortality is comparable to the effect of gaining a full pound in birth weight (Almond et al. 2005)—about ten times the effect of Food Stamp implementation birth weight among treated black infants (Almond et al. 2011). Chay and Greenstone (2003) find that improvements in air quality that followed the 1970 Clean Air Act reduced neonatal infant mortality by about 18 percent. The desegregation of Southern hospitals led to a larger reduction—about 50 percent—in black post-neonatal mortality (Almond et al. 2006), which may follow from the clear course of treatment for babies with severe gastrointestinal disease. The infant mortality effects are also comparable to those of many public

\footnotetext{
51 The confidence intervals in figure 10 assume zero correlation between the components of the ATET. Appendix 4 presents confidence interval estimates under a series of assumptions about the correlation between the reduced form and first-stage effects. The confidence intervals never include zero for any value of the correlation, although they are wider when the two parameters are positively correlated. Notably, the confidence interval for age-adjusted mortality also never crosses -100 percent. I thank Alejandro Molnar for this suggestion.

${ }^{52}$ Another measure of the size of the treatment effects is the "number needed to treat" to avert one death (NNT), which equals the inverse of the absolute reduction in mortality risk. One advantage of this parameter over a proportional ATET is that it reflects secular changes in mortality rates. Between 1966 and 1979, the average NNT based on the age-adjusted effects is 915 children, but grows from 548 in 1966 (when counterfactual mortality among treated children was 840.2 deaths per 100,000) to 1,403 in 1979 (when counterfactual mortality among treated children had fallen to 356.6 deaths per 100,000). Average NNT for neonates is 97 (ranging from 75 to 130), and 1,204 for young children (ranging from 703 to 1,695).
} 
health programs. For example, the installation of lead pipes at the turn of the century increased infant mortality by "between 25 and 50 percent” (Troesken 2003), and investments in water sanitation facilities on Indian reservations could have reduced infant mortality by as much as 25 percent (Watson 2006).

The ATETs from the 1980s expansions on the other hand are much larger than the effects in this paper. The estimates imply a 99 percent mortality reduction for infants, a 188 percent reduction for children, and an 84 percent reduction for black teens. ${ }^{53}$ This is surprising since the AFDC children who gained insurance because of Medicaid implementation were poorer and less healthy than many of the groups who gained coverage in the 1980s. Improved technology, particularly artificial lung-surfactant for premature infants may explain some of the bigger effects in the 1980s (Bharadwaj et al. 2013). Another interpretation is that some of the other consequences of the 1980s expansions-increased consumption for crowd-out families or take up of other programs-were not at work in the 1960s, when categorically eligible families spent little on medical care and received welfare by definition. This suggests that the mortality reductions documented here reflect the effect of new Medicaid coverage itself, and that Medicaid's effect per eligible person in the 1980s reflects additional causal channels. ${ }^{54}$ What do these effects imply for current Medicaid policy? While discussions of external validity are necessarily informal, this is an important caveat for any historical evaluation. Some channels documented above, such as increases in hospital births, are not relevant for low-income families today, while others, such as hospital switching, have continued to be important mechanisms for improving infant survival (Aizer et al. 2004). Improvements in medical technology also mean that losing Medicaid coverage today may imply a larger cost in terms of health than in the past. The extent to which these

\footnotetext{
${ }^{53}$ The RD mortality estimate in Wherry and Meyer (2013) is based on differences in cumulative eligibility and mortality rates observed years after the discontinuity arose. The RD estimates for insurance coverage, however, refer to contemporaneous coverage (Card and Shore-Sheppard 2004). The dynamics of Medicaid participation, therefore, mean that the true longer-run first stage (cumulative participation) could be larger or smaller than assumed here.

${ }^{54}$ Scaling the ITT by eligibility instead of new coverage yields a proportional reduction in mortality of 28 percent per eligible infant (Currie and Gruber 1996b, pp. 1276) and 34 percent per eligible child (Currie and Gruber 1996a, pp. 454).
} 
estimates apply to children who would be affected by current Medicaid reform proposals is an open question, but given the lack of policy variation for children, this paper provides clear new support for the notion that Medicaid—in any era—improves child health.

\section{B. $\quad$ Medicaid's Aggregate Costs and Benefits}

The results not only imply an important reduction in individual-level mortality risk, but also a major role for Medicaid implementation in aggregate mortality changes in the 1960s and 1970s. By 1976, about 35 percent of nonwhite children used Medicaid. Appendix table 4.4 uses survey data to show that the mortality rate among poor (ie. treated) children was about 1.8 times the average in the mid-1960s, and (partly due to Medicaid) about 1.3 times the average by the 1980s. To calculate mortality among treated children in each year, I linearly interpolate this ratio from 1.8 to 1.3 between 1966 and 1979, and multiply it by observed age-adjusted child mortality. The implied mortality rate among treated (ie. poor) children in 1976 is 357.7 deaths per 100,000 (compared to the average of 252.7). Since these children experienced a -20 percent ATET, their actual mortality is 80 percent of their counterfactual mortality rate $(447.3=357.7 / 0.8)$, and the ATET in levels (in 1976) is -89.4 deaths per 100,000 $(-0.2 * 447.3)$. Adding this effect times the share of nonwhite children who received Medicaid (0.35) to the aggregate mortality rate implies that without Medicaid nonwhite age-adjusted child mortality would have been 284 (252.7+0.35*89.4). Thus, Medicaid implementation reduced aggregate mortality by 11 percent ([284252.7]/284) and the poverty gap in nonwhite child mortality by a third (the counterfactual mortality gap is 250.7 deaths per 100,000). See appendix $2 \mathrm{~F}$ for detail on these calculations.

These calculations all refer to Medicaid's effect on period mortality rates, while the actual benefits accrued over time. Comparing the observed number of nonwhite child deaths to the counterfactual number in each year suggest that, between 1966 and 1979, 35,087 nonwhite deaths were averted due to Medicaid (2,506 deaths per year). Most of these deaths would have occurred among neonates and young 
children, for whom the remaining life expectancy in 1966 was about 65.5 (NCHS 1966), which implies a gain of 2.3 million life-years saved.

Through 1976, Medicaid spent about $\$ 5.8$ billion (in 2012 dollars) per year on all children ages 0 to 19. Assuming that expenditures on children ages 0 to 14 were proportional to their share of child Medicaid recipients (78 percent in 1976), and that no white children benefited, this implies a cost per death averted of about $\$ 1.83$ million and a discounted cost per life-year saved of about $\$ 64,000 .^{55}$ Infant deaths were significantly cheaper to avoid than deaths among young children: the cost per death averted is $\$ 170,000$ for nonwhite neonates and $\$ 2.2$ million for young nonwhite children. Comparable estimates from Currie and Gruber (1996b; 1996a) are about \$1.7 million and \$2.6 million (2012 dollars) per infant and child death averted, which shows that Medicaid achieved mortality reductions at this time for a fraction of the cost of more recent expansions.

These costs only refer to the contemporaneous expenditures relative to life years gained, but Medicaid's benefits may extend into later life health (Miller and Wherry 2014; Boudreaux et al. forthcoming), educational attainment (Cohodes et al. 2014), and increased tax receipts (Brown et al. 2014). To the extent that early health investments of Medicaid implementation complement later-life health production, human capital investments and labor supply, the life-cycle benefits of Medicaid may add to the contemporaneous benefits documented here.

\section{CONCLUSION}

This paper provides new evidence on the relationship between Medicaid and mortality using the original introduction of the program between 1966 and 1970. The results are the first to examine Medicaid implementation and suggest that the program was quite well targeted during this period: nonwhite infants and children suffered very high mortality rates in the 1960s, used Medicaid the most,

\footnotetext{
${ }^{55}$ A discount rate of 3 percent and the assumption that the private value of additional life years is constant across ages implies that the present discounted dollar value of 65 additional life years is equivalent to an immediate payout of 28.7 times the value of an additional year: $\left(1-0.97^{65}\right) /(1-0.97)=28.7$.
} 
and experienced the largest mortality reductions. More recent policy changes have had similar qualitative effects on infant and child mortality, this paper's estimates are among the only quasiexperimental results that are small enough to be attributed to Medicaid coverage itself. These findings presumably understate Medicaid's broader effects because they only measure benefits in terms of mortality rather than reductions in morbidity or delayed health and productivity effects. Therefore Medicaid, like several other federal health and anti-poverty programs established under the Great Society, played a major role in improving health and reducing mortality in the 1960s and 1970s.

Author Affiliations:

Andrew Goodman-Bacon is a Robert Wood Johnson Health Policy Scholar at the University of California, Berkeley 


\section{REFERENCES}

Advisory Commission on Intergovernmental Relations, Intergovernmental Problems in Medicaid: a Commission Report (Washington, DC, 1968).

Aizer, Anna, Adriana Lleras-Muney, and Mark Stabile, "Access to Care, Provider Choice and Racial Disparities," National Bureau of Economic Research Working Paper Series, No. 10445 (2004).

Aizer, Anna, and Laura Stroud, "Education, Knowledge and the Evolution of Disparities in Health," National Bureau of Economic Research Working Paper Series, No. 15840 (2010).

Alexander, Gregory R., and Milton Kotelchuck, "Assessing the Role and Effectiveness of Prenatal Care: History, Challenges, and Directions for Future Research," Public Health Rep, 116 (2001), 306-317.

Almond, Douglas, Kenneth Y. Chay, and Michael Greenstone, "Civil Rights, the War on Poverty, and Black-White Convergence in Infant Mortality in the Rural South and Mississippi," MIT Department of Economics Working Paper, No. 07-04. (2006).

Almond, Douglas, Kenneth Y. Chay, and David S. Lee, "The Costs of Low Birth Weight," The Quarterly Journal of Economics, 120 (2005), 1031-1083.

Almond, Douglas, Hilary W. Hoynes, and Diane Whitmore Schanzenbach, "Inside the War On Poverty: The Impact of Food Stamps on Birth Outcomes," The Review of Economics and Statistics, 93 (2011), 387-403.

Alston, Lee J., and Joseph P. Ferrie, "Labor Costs, Paternalism, and Loyalty in Southern Agriculture: A Constraint on the Growth of the Welfare State," The Journal of Economic History, 45 (1985), 95-117.

Baicker, Katherine, Sarah L. Taubman, Heidi L. Allen, Mira Bernstein, Jonathan H. Gruber, Joseph P. Newhouse, Eric C. Schneider, Bill J. Wright, Alan M. Zaslavsky, and Amy N. Finkelstein, "The Oregon Experiment Effects of Medicaid on Clinical Outcomes," New England Journal of Medicine, 368 (2013), 1713-1722.

Bailey, Martha J., and Andrew Goodman-Bacon, "The War on Poverty's Experiment in Public Medicine: Community Health Centers and the Mortality of Older Americans," American Economic Review, 105 (2015), 1067-1104.

Beeson, Paul B., "Changes in Medical Therapy During the Past Half Century," Medicine, 59 (1980), 79-99.

Bell, Winifred, Aid to Dependent Children (New York: Columbia University Press, 1965).

Bernard, Sydney E., and Eugene Feingold, "The Impact of Medicaid," Wisconsin Law Review, (1970), 726-755.

Bertrand, Marianne, Esther Duflo, and Sendhil Mullainathan, "How Much Should We Trust Differences-InDifferences Estimates?," The Quarterly Journal of Economics, 119 (2004), 249-275.

Bharadwaj, Prashant, Katrine Vellesen Løken, and Christopher Neilson, "Early Life Health Interventions and Academic Achievement," American Economic Review, 103 (2013), 1862-1891.

Bitler, Marianne P., and Janet Currie, "Medicaid at Birth, WIC Take Up, and Children's Outcomes," RAND Working Paper, WR-172 (2004).

Bitler, Marianne P., Jonah B. Gelbach, and Hilary W. Hoynes, "Welfare Reform and Health," The Journal of Human Resources, 40 (2005), 309-334.

Boudreaux, Michel, Ezra Golberstein, and Donna McAlpine, "The Long-Term Impacts of Medicaid Exposure in Early Childhood: Evidence from the Program's Origin," Journal of Health Economics, (forthcoming).

Brown, David, Amanda Kowalski, and Ithai Lurie, "Medicaid as an Investment in Children: What is the Long-Term Impact on Tax Receipts?," Yale University Department of Economics Working Paper Series, (2014).

Budetti, Peter P., and Peggy McManus, "Assessing the Effectiveness of Neonatal Intensive Care," Medical Care, 20 (1982), 1027-1039.

California Public Health Service, "Impact of Medi-Cal on Perinatal Mortality in California," (Sacramento, CA: State of California, Department of Public Health, 1973).

Cameron, A. Colin, Jonah B. Gelbach, and Douglas L. Miller, "Bootstrap-Based Improvements for Inference with Clustered Errors," Review of Economics and Statistics, 90 (2008), 414-427.

Card, David, Andrew K. G. Hildreth, and Lara D. Shore-Sheppard, "The Measurement of Medicaid Coverage in the SIPP: Evidence from a Comparison of Matched Records," Journal of Business \& Economic Statistics, 22 (2004), 410-420.

Card, David, and Lara D. Shore-Sheppard, "Using Discontinuous Eligibility Rules to Identify the Effects of the Federal Medicaid Expansions on Low-Income Children," The Review of Economics and Statistics, 86 (2004), 752-766.

Cecil, Russell L., Robert Frederick Loeb, Paul B. Beeson, and Walsh McDermott, Cecil-Loeb Textbook of Medicine 12th ed. (Philadelphia: Saunders, 1967).

Center for Health Administration Studies, and National Opinion Research Center, "Survey of Health Services Utilization and Expenditures, 1963," (Inter-university Consortium for Political and Social Research (ICPSR) [distributor], 1984a). 
---, "Survey of Health Services Utilization and Expenditures, 1970," (ICPSR [distributor], 1984b).

Center for Medicare and Medicaid Services, "Medicare \& Medicaid Statistical Supplement 2012 Edition," in Medicare \& Medicaid Statistical Supplement, (2012).

Chay, Kenneth Y., and Michael Greenstone, "Air Quality, Infant Mortality, and the Clean Air Act of 1970," National Bureau of Economic Research Working Paper Series, No. 10053 (2003).

Chay, Kenneth Y., Jonathan Guryan, and Bhashkar Mazumder, "Birth Cohort and the Black-White Achievement Gap: The Roles of Access and Health Soon After Birth," National Bureau of Economic Research Working Paper Series, No. 15078 (2009).

Cohen, Robin A., and Michael E. Martinez, "Health Insurance Coverage: Early Release of Estimates From the National Health Interview Survey, 2012," in The National Health Interview Survey Early Release Program, National Center for Health Statistics., ed. (2013).

Cohodes, Sarah, Samuel Kleiner, Michael F. Lovenheim, and Daniel Grossman, "The Effect of Child Health Insurance Access on Schooling: Evidence from Public Insurance Expansions," National Bureau of Economic Research Working Paper Series, No. 20178 (2014).

Collins, William J., and Melissa A. Thomasson, "The Declining Contribution of Socioeconomic Disparities to the Racial Gap in Infant Mortality Rates, 1920-1970," Southern Economic Journal, 70 (2004), 746-776.

Committee on Ways and Means of the House of Representatives, Medical Resources Available to Meet the Needs of Public Assistance Recipients. A Report (Washington,: U.S. Govt. Print. Off., 1961).

Currie, Janet, and Nancy Cole, "Welfare and Child Health: The Link Between AFDC Participation and Birth Weight," The American Economic Review, 83 (1993), 971-985.

Currie, Janet, and Jonathan Gruber, "Health Insurance Eligibility, Utilization of Medical Care, and Child Health," The Quarterly Journal of Economics, 111 (1996a), 431-466.

---, "Saving Babies: The Efficacy and Cost of Recent Changes in the Medicaid Eligibility of Pregnant Women," Journal of Political Economy, 104 (1996b), 1263-1296.

---, "Public health insurance and medical treatment: the equalizing impact of the Medicaid expansions," Journal of Public Economics, 82 (2001), 63-89.

Cutler, David M., and Jonathan Gruber, "Does Public Insurance Crowd Out Private Insurance," The Quarterly Journal of Economics, 111 (1996), 391-430.

Cutler, David M., and Ellen Meara, "The Technology of Birth: Is it Worth it?," National Bureau of Economic Research Working Paper Series, No. 7390 (1999).

---, "Changes in The Age Distribution of Mortality Over the 20th Century," in A National Bureau of Economic Research conference report: Perspectives on the economics of aging, David A. Wise, ed. (Chicago: University of Chicago Press, 2004).

Dave, Dhaval M., Sandra Decker, Robert Kaestner, and Kosali I. Simon, "Re-examining the Effects of Medicaid Expansions for Pregnant Women," National Bureau of Economic Research Working Paper Series, No. 14591 (2008).

Davern, Michael, Jacob Alex Klerman, and Jeanette Ziegenfussi, "Medicaid Under-reporting in the Current Population Survey and One Approach for a Partial Correction," Rand Corporation, ed. (Santa Monica, CA, 2007).

David, Richard J., and Earl Siegel, "Decline in Neonatal Mortality, 1968 to 1977: Better Babies or Better Care?," Pediatrics, 71 (1983), 531-540.

Davis, Karen, and Cathy Schoen, Health and the War on Poverty : a Ten-Year Appraisal (Washington: Brookings Institution, 1978).

Deaton, Angus, The Analysis of Household Surveys : a Microeconometric Approach to Development Policy (Baltimore, MD: Johns Hopkins University Press, 1997).

Decker, Sandra, and Jonathan Gruber, "Public Policy and Infant Outcomes: The Effect of Introducing the Medicaid Program," Unpublished Manuscript, (1993).

Department of Health, Education, and Welfare, "Volume II, Marriage, Divorce, Natality, Fetal Mortality and Infant Mortality Data," in Vital Statistics of the United States, (Washington, D.C.: U.S. Government Printing Office, 1953a).

---, "Volume III, Mortality Data," in Vital Statistics of the United States, (Washington, D.C.: U.S. Government Printing Office, 1953b).

---, "Volume I, Introduction and Text Tables. Tables for Alaska, Hawaii, Puerto Rico, and Virgin Islands. Marriage, Divorce, Natality, Fetal Mortality and Infant Mortality Data," in Vital Statistics of the United States, (Washington, D.C.: U.S. Government Printing Office, 1954-1964a). 
---, "Volume II, Mortality Data," in Vital Statistics of the United States, (Washington, D.C.: U.S. Government Printing Office, 1954-1964b).

---, "Characteristics of Families Receiving Aid to Families with Dependent Children, November-December 1961," Bureau of Family Services Welfare Administration, Division of Program Statistics and Analysis., ed. (1963).

---, "Tables Derived from Form FS-2036, Annual Statistical Report of Medical and Remedial Care Provided Through Public Assistance Vendor Payments, Fiscal Year 1963," Bureau of Family Services Welfare Administration, Division of Program Analysis and Statistics, ed. (Washington D.C., 1965).

---, "Advanced Release of Statistics on Public Assistance, January 1966," Bureau of Family Services Welfare Administration, Research Division., ed. (Washington, D.C., 1966).

---, "Handbook of Public Assistance Administration Supplement D, Medical Assistance Programs Under Title XIX of the Social Security Act," Medical Services Administration Social and Rehabilitation Service, ed. (Washington, D.C., 1967a).

---, "Recipients and Amounts of Medical Vendor Payments under Public Assistance Programs, July - December 1965," Bureau of Family Services Welfare Administration, Division of Program Analysis and Statistics, ed. (Washington D.C., 1967b).

---, "Recipients of Medical Vendor Payments under Public Assistance Programs, January - June 1966," Bureau of Family Services Welfare Administration, Division of Research, ed. (Washington D.C., 1967c).

---, "Utilization of Medical Care Paid for Through Public Assistance Payments to Vendors, Fiscal Year 1964-1965," Bureau of Family Services Welfare Administration, Division of Program Analysis and Statistics, ed. (Washington D.C., 1967d).

---, "Recipients and Amounts of Medical Vendor Payments under Public Assistance Programs, July - December 1966," Social and Rehabilitation Service, ed. (Washington D.C., 1968).

---, "Recipients and Amounts of Medical Vendor Payments under Public Assistance Programs, July - December 1967," National Center for Social Statistics Social and Rehabilitation Service, ed. (Washington D.C., 1969).

---, "Numbers of Recipients and Amounts of Payments Under Medicaid and Other Medical Programs Financed by Public Assistance Funds 1968," Office of Program Statistics and Data Systems Social and Rehabilitation Service, National Center for Social Statistics, ed. (Washington D.C., 1971a).

---, "Recipients and Amounts of Medical Vendor Payments under Public Assistance Programs, January - June 1969," National Center for Social Statistics Social and Rehabilitation Service, ed. (Washington D.C., 1971b).

---, "Numbers of Recipients and Amounts of Payments Under Medicaid and Other Medical Programs Financed by Public Assistance Funds 1969," Office of Program Statistics and Data Systems Social and Rehabilitation Service, National Center for Social Statistics, ed. (Washington D.C., 1972a).

---, "Numbers of Recipients and Amounts of Payments Under Medicaid and Other Medical Programs Financed by Public Assistance Funds 1970," Office of Program Statistics and Data Systems Social and Rehabilitation Service, National Center for Social Statistics, ed. (Washington D.C., 1972b).

---, "Medicaid Recipient Characteristics and Units of Selected Medical Services 1972.," Office of Information Systems Social and Rehabilitation Service, National Center for Social Statistics, ed. (Washington D.C., 1974a).

---, "Numbers of Recipients and Amounts of Payments Under Medicaid Fiscal Year 1972," Office of Information Systems Social and Rehabilitation Service, National Center for Social Statistics, ed. (Washington D.C., 1974b).

---, "Numbers of Recipients and Amounts of Payments Under Medicaid Fiscal Year 1973," Office of Information Systems Social and Rehabilitation Service, National Center for Social Statistics, ed. (Washington D.C., 1975a).

---, "State Tables Fiscal Year 1975, Medicaid: Recipients, Payments, and Services," Office of Policy Health Care Financing Administration, Planning, and Research, ed. (Washington D.C., 1975b).

---, "Medicaid State Tables Fiscal Year 1976: Recipients, Payments, and Services," Office of Policy Health Care Financing Administration, Planning, and Research, ed. (Washington D.C., 1976a).

---, "Numbers of Recipients and Amounts of Payments Under Medicaid Fiscal Year 1974," Office of Information Systems Social and Rehabilitation Service, National Center for Social Statistics, ed. (Washington D.C., 1976b).

---, "AFDC Data for Assistance Units and Persons, 1979," (U.S. Department of Health and Human Services. Office of the Assistant Secretary for Planning and Evaluation., 2000). 
---, "Surveys of Recipients of Aid to Families with Dependent Children, 1967-1977," National Center for Social Statistics Social and Rehabilitation Service, Population Surveys Branch, ed. (National Archives and Records Administration. Social Security Agency., 2011).

Desmond, Murdina M., Newborn medicine and society : European background and American practice, 1750-1975 (Austin, TX: Eakin Press, 1998).

DuMouchel, William H., and Greg J. Duncan, "Using Sample Survey Weights in Multiple Regression Analyses of Stratified Samples," Journal of the American Statistical Association, 78 (1983), 535-543.

Efron, Bradley, and Robert Tibshirani, An Introduction to the Bootstrap (New York: Chapman \& Hall, 1993).

Evans, William N., and Diana S. Lien, "The benefits of prenatal care: evidence from the PAT bus strike," Journal of Econometrics, 125 (2005), 207-239.

Finkelstein, Amy, "The Aggregate Effects of Health Insurance: Evidence from the Introduction of Medicare," The Quarterly Journal of Economics, 122 (2007), 1-37.

Finkelstein, Amy, and Robin McKnight, "What Did Medicare Do? The Initial Impact of Medicare on Mortality and Out of Pocket Medical Spending," Journal of Public Economics, 92 (2008), 1644-1668.

Finkelstein, Amy, Sarah Taubman, Bill Wright, Mira Bernstein, Jonathan Gruber, Joseph P. Newhouse, Heidi Allen, Katherine Baicker, and Oregon Health Study Group, "The Oregon Health Insurance Experiment: Evidence from the First Year," The Quarterly Journal of Economics, 127 (2012), 1057-1106.

Fiscella, Kevin, "Does Prenatal Care Improve Birth Outcomes? A Critical Review," Obstetrics \& Gynecology, 85 (1995), 468-479.

Freedman, Seth, Haizhen Lin, and Kosali Simon, "Public health insurance expansions and hospital technology adoption," Journal of Public Economics, 121 (2015), 117-131.

Ginzberg, Eli, and Robert M. Solow, The Great Society : Lessons for the Future (New York: Basic Books, 1974).

Grannemann, Thomas W., and Mark V. Pauly, Controlling Medicaid Costs : Federalism, Competition, and Choice (Washington, D.C.: American Enterprise Institute for Public Policy Research, 1983).

Gruber, Jonathan, "Medicaid," in Means-Tested Transfer Programs in the United States, Robert Moffitt, ed. (Chicago: University of Chicago Press, 2003).

Gruber, Jonathan , and Aaron Yelowitz, "Public Health Insurance and Private Savings," Journal of Political Economy, 107 (1999), 1249-1274.

Hanratty, Maria J., "Canadian National Health Insurance and Infant Health," The American Economic Review, 86 (1996), 276-284.

Harris, Richard O., "A Sacred Trust " in The New Yorker, (New York: Conde Nast, 1966).

Health Insurance Council, "Report on Annual Survey; the Extent of Voluntary Health Insurance Coverage in the United States," (New York, NY, 1953-1959).

Health Insurance Institute, "Source Book of Health Insurance Data," (New York, NY, 1959-1982).

Hoynes, Hilary, Marianne Page, and Ann Huff Stevens, "Can Targeted Transfers Improve Birth Outcomes?: Evidence from the Introduction of the WIC Program," Journal of Public Economics, 95 (2011), 813-827.

Jacobson, Louis S., Robert J. LaLonde, and Daniel G. Sullivan, "Earnings Losses of Displaced Workers," The American Economic Review, 83 (1993), 685-709.

Johnston, Jack, and John DiNardo, Econometric Methods 4th ed. (New York: McGraw-Hill, 1997).

Kaiser Family Foundation, "The Medicaid Program at a Glance," (http://kff.org/medicaid/, 2013).

Klarman, Herbert E., "Major Public Initiatives in Health Care," in The Great Society : Lessons for the Future, Eli Ginzberg, and Robert M. Solow, eds. (New York: Basic Books, 1974).

Kovar, Mary Grace, Interim Report on Health Insurance, United States, July-December 1959 (Washington,: U. S. Dept. of Health, Education, and Welfare, Public Health Service, 1960).

Kutinova, Andrea, and Karen Smith Conway, "What about Mom? The Forgotten Beneficiary of the Medicaid Expansions," Southern Economic Journal, 74 (2008), 1070-1104.

Lee, Kwang-Sun, Nigel Paneth, Lawrence M. Gartner, Mark A. Pearlman, and Leslie Gruss, "Neonatal Mortality: an Analysis of the Recent Improvement in the United States," American Journal of Public Health, 70 (1980), $15-21$.

Leininger, Lindsey , Helen Levy, and Diane Schanzenbach, "Consequences of SCHIP Expansions for Household Well-Being," Forum for Health Economics \& Policy, 13 (2012).

Leonard, Jonathan, and Alexandre Mas, "Welfare Reform, Time Limits, and Infant Health," Journal of Health Economics, 27 (2008), 1551-1566.

Levy, Helen, and David Meltzer, "What Do We Really Know About Whether Health Insurance Affects Health?," in Health Policy and the Uninsured, Catherine G. McLaughlin, ed. (Washington, D.C.: Urban Institute Press, 2004). 
Loewenstein, Regina, "The Effect of Medicaid on Health Care of Low-Income Families," in Report of Contracts with Social Rehabilitation Service, (New York, NY: School of Public Health, Columbia University, 1971).

Long, Stephen H., and M. Susan Marquis, "The Effects of Florida's Medicaid Eligibility Expansion for Pregnant Women," American Journal of Public Health, 88 (1998), 371-376.

Ludwig, Jens, and Douglas L. Miller, "Does Head Start Improve Children's Life Chances? Evidence from a Regression Discontinuity Design," The Quarterly Journal of Economics, 122 (2007), 159-208.

Matusow, Allen J., The Unraveling of America: a History of Liberalism in the 1960s 1st ed. (New York: Harper \& Row, 1984).

Miller, Sarah, and Laura R. Wherry, "The Long-Term Health Effects of Early Life Medicaid Coverage," University of Michigan Working Paper, (2014).

Minnesota Population Center and State Health Access Data Assistance Center, "Integrated Health Interview Series: Version 5.0.," (Minneapolis: University of Minnesota, . 2012).

Moehling, Carolyn M, "The American Welfare System and Family Structure An Historical Perspective," Journal of Human Resources, 42 (2007), 117-155.

Moffitt, Robert, "Historical Growth in Participation in Aid to Families with Dependent Children: Was There a Structural Shift?," Journal of Post Keynesian Economics, 9 (1987), 347-363.

Morgan, James N., Martin H. David, Wilbur J. Cohen, and Harvey E. Brazer, Income and Welfare in the United States, A Study by the Survey Research Center, Institute for Social Research, University of Michigan (New York,: McGraw-Hill, 1962).

Mugge, Robert, "Characteristics and Financial Circumstances of Families Receiving Aid to Dependent Children, Late 1958," Department of Health, Education, and Welfare, ed. (Washington, D.C., 1960).

National Center for Health Statistics, "Vital and Health Statistics. Series 22, Data from the National Vital Statistics System," in No 1-, Public Health Service publication, (Washington, D.C.: U.S. Dept. of Health, Education, and Welfare, 1965).

---, "Vital Statistics of the United States. Volume II, Section 5, Life Tables," (Washington, D.C.: U.S. Dept. of Health, Education, and Welfare, Public Health Service, National Vital Statistics Division, 1966).

---, "Health, United States 1975-1976/77, 1979," (Rockville, Md.: U.S. Dept. of Health, Education, and Welfare, Public Health Service, Health Resources Administration, 1976).

Pauly, Mark V., and José A. Pagán, "Spillovers And Vulnerability: The Case Of Community Uninsurance," Health Aff (Millwood), 26 (2007), 1304-1314.

Piper, Joyce M., Wayne A. Ray, and Marie R. Griffin, "EFfects of Medicaid Eligibility Expansion on Prenatal Care and Pregnancy Outcome in Tennessee," Journal of the American Medical Association, 264 (1990), 22192223.

Roghmann, Klaus J., Robert J. Haggerty, and Rodney Lorenz, "Anticipated and Actual Effects of Medicaid on the Medical-Care Pattern of Children," New England Journal of Medicine, 285 (1971), 1053-1057.

Sanders, Nicholas J., and Charles Stoecker, "Where have all the young men gone? Using sex ratios to measure fetal death rates," Journal of Health Economics, 41 (2015), 30-45.

Shore-Sheppard, Lara D. , "Stemming the Tide? The Effect of Expanding Medicaid Eligibility On Health Insurance Coverage," The B.E. Journal of Economic Analysis \& Policy, 8 (2009).

Smith, Dennis, and Edmund Haislmeier, "Medicaid Meltdown: Dropping Medicaid Could Save States \$1 Trillion," (http://www.heritage.org/: Heritage Foundation, 2009).

Solon, Gary, Steven J. Haider, and Jeffrey Wooldridge, "What Are We Weighting For?," Journal of Human Resources, 50 (2015), 301-316.

Sommers, Benjamin D., Katherine Baicker, and Arnold M. Epstein, "Mortality and Access to Care among Adults after State Medicaid Expansions," New England Journal of Medicine, 367 (2012), 1025-1034.

Stephens, Melvin, Jr., and Dou-Yan Yang, "Compulsory Education and the Benefits of Schooling," National Bureau of Economic Research Working Paper Series, No. 19369 (2013).

Strumpf, Erin, "Medicaid's Effect on Single Women's Labor Supply: Evidence from the Introduction of Medicaid," Journal of Health Economics, 30 (2011), 531-548.

Sylla, Richard E., John B. Legler, and John Wallis, "State and Local Government [United States]: Sources and Uses of Funds, Census Statistics, Twentieth Century [Through 1982]," (Inter-university Consortium for Political and Social Research (ICPSR) [distributor], 2006).

Tax Foundation, Medicaid: State Programs After Two Years (New York, 1968).

Troesken, Werner, "Lead Water Pipes and Infant Mortality in Turn-of-the-Century Massachusetts," National Bureau of Economic Research Working Paper Series, No. 9549 (2003). 
United States Department of Commerce, and Bureau of the Census, "Survey of Income and Education, 1976," (ICPSR [distributor], 2006).

United States Department of Health and Human Services, "Multiple Cause of Death, Various Years," National Center for Health Statistics, ed. (ICPSR [distributor], 2009).

United States Department of Health and Human Services, Administration for Children and Families, and Office of Family Assistance, "Caseload Data 1960 - 1999," (2012).

United States Department of Health and Human Services, Centers for Disease Control and Prevention, and National Center for Health Statistics, "Health Interview Survey, 1963," (ICPSR [distributor], 2010a).

---, "Health Interview Survey, 1968," (ICPSR [distributor], 2010b).

---, "Health Interview Survey, 1974," (ICPSR [distributor], 2010c).

United States Department of Health and Human Services, and National Center for Health Statistics, "Natality Detail File, Various Years," (ICPSR [distributor], 2002).

Watson, Tara, "Public Health Investments and the Infant Mortality Gap: Evidence from Federal Sanitation Interventions on U.S. Indian Reservations," Journal of Public Economics, 90 (2006), 1537-1560.

Wherry, Laura R., and Bruce D. Meyer, "Saving Teens: Using a Policy Discontinuity to Estimate the Effects of Medicaid Eligibility," National Bureau of Economic Research Working Paper Series, No. 18309 (2013).

Williams, Ronald L., and Peter M. Chen, "Identifying the Sources of the Recent Decline in Perinatal Mortality Rates in California," New England Journal of Medicine, 306 (1982), 207-214.

Yazici, Esel Y., and Robert Kaestner, "Medicaid Expansions and the Crowding Out of Private Health Insurance Among Children," Inquiry - Blue Cross and Blue Shield Association, 37 (2000), 23-32. 
Table 1. Balancing Test: The Relationship between Initial AFDC Rates and Pre-Medicaid Levels of and Linear Trends in State Characteristics

(1)

(2)

(3)

(4)

(5)

(6)

Nonwhite

\begin{tabular}{|c|c|c|c|c|c|c|}
\hline \multirow[b]{2}{*}{ Dependent Variable } & & \\
\hline & $\begin{array}{c}\text { Pre- } \\
\text { Medicaid } \\
\text { Mean } \\
\end{array}$ & $\begin{array}{c}\text { Level } \\
\left(A F D C_{S}^{*}\right)\end{array}$ & $\begin{array}{c}\text { Trend } \\
\left(A F D C_{s}^{*} \times \text { Year }\right)\end{array}$ & $\begin{array}{l}\text { Pre- } \\
\text { Medicaid } \\
\text { Mean }\end{array}$ & $\begin{array}{c}\text { Level } \\
\left(A F D C_{s}^{*}\right)\end{array}$ & $\begin{array}{c}\text { Trend } \\
\left(A F D C_{s}^{*} \times \text { Year }\right)\end{array}$ \\
\hline & \multicolumn{6}{|c|}{ A. Demographic Outcomes 1950-1965 (measured by race) } \\
\hline \multirow[t]{2}{*}{ Child Mortality } & 425.6 & 1.72 & 0.13 & 206.8 & 2.22 & 0.06 \\
\hline & & {$[2.61]$} & {$[0.15]$} & & [2.83] & {$[0.71]$} \\
\hline \multirow[t]{2}{*}{ Infant Mortality } & 40.6 & 0.08 & 0.01 & 21.5 & 0.05 & -0.03 \\
\hline & & {$[0.22]$} & {$[0.01]$} & & {$[0.22]$} & {$[0.07]$} \\
\hline \multirow[t]{2}{*}{ Very Low Birth Weight } & 23.2 & 0.12 & 0.0002 & 10.1 & -0.09 & -0.01 \\
\hline & & {$[0.17]$} & {$[0.0066]$} & & {$[0.15]$} & {$[0.01]$} \\
\hline \multirow[t]{3}{*}{ Low Birth Weight } & 138.7 & -0.39 & -0.07 & 71.6 & 2.23 & -0.10 \\
\hline & & {$[0.45]$} & {$[0.04]$} & & {$[1.87]$} & {$[0.08]$} \\
\hline & \multicolumn{6}{|c|}{ B. Socioeconomic Outcomes 1950 and 1960 (measured by race) } \\
\hline \multirow[t]{2}{*}{ Poverty $(0-14)$} & 56.9 & -0.80 & -0.02 & 20.2 & -0.53 & -0.07 \\
\hline & & {$[0.75]$} & {$[0.02]$} & & {$[3.0]$} & {$[0.10]$} \\
\hline \multirow[t]{2}{*}{ Living w/o Father (0-14) } & 29.4 & 0.11 & -0.01 & 7.4 & 1.00 & 0.03 \\
\hline & & {$[0.13]$} & {$[0.02]$} & & {$[0.43]$} & [0.03] \\
\hline \multirow[t]{2}{*}{ Median Earnings (25-44) } & 2,999 & 30.69 & 2.51 & 4,675 & 132.10 & 12.37 \\
\hline & & [37.73] & [1.69] & & {$[217.80]$} & [12.45] \\
\hline \multirow[t]{2}{*}{ Grade $12+(25-44)$} & 34.0 & 0.25 & 0.001 & 58.3 & 1.46 & -0.03 \\
\hline & & {$[0.45]$} & {$[0.01]$} & & [2.41] & {$[0.07]$} \\
\hline \multirow[t]{3}{*}{ AFDC Benefit (1967) } & 154.2 & 3.10 & & 147.4 & 10.85 & \\
\hline & & [1.39] & & & {$[10.41]$} & \\
\hline & \multicolumn{6}{|c|}{ C. Other Outcomes (not measured by race) } \\
\hline \multirow[t]{2}{*}{$\begin{array}{l}\text { Log Public Exp. per 1,000 } \\
(1932,1942,1962)\end{array}$} & 6.9 & -0.002 & -0.001 & 6.9 & 0.17 & 0.0003 \\
\hline & & {$[0.01]$} & {$[0.001]$} & & {$[0.07]$} & {$[0.003]$} \\
\hline \multirow[t]{2}{*}{$\begin{array}{l}\text { Hospital Beds per 1,000 } \\
(1950-1965)\end{array}$} & 4.9 & 0.03 & -0.001 & 4.9 & 0.09 & 0.0001 \\
\hline & & {$[0.03]$} & {$[0.001]$} & & {$[0.20]$} & {$[0.0119]$} \\
\hline \multirow[t]{2}{*}{$\begin{array}{l}\text { Hospital Ins. per 1,000 } \\
(1952-1965)\end{array}$} & 818.5 & -0.63 & -0.37 & 817.9 & -10.56 & 0.74 \\
\hline & & [4.77] & {$[0.26]$} & & [27.72] & [1.74] \\
\hline \multirow[t]{2}{*}{$\begin{array}{l}\text { Medical Ins. per 1,000 } \\
(1952-1965)\end{array}$} & 591.3 & 7.79 & -0.04 & 591.2 & 51.00 & -0.19 \\
\hline & & [5.71] & {$[0.40]$} & & [35.39] & [2.43] \\
\hline
\end{tabular}

Notes: The table presents (weighted) estimates from the following model: $y_{s t}=\alpha+\beta_{0} A F D C_{s}^{*}+\beta_{1} A F D C_{s}^{*} \times\left(y-y^{P R E}\right)+$ $u_{s t} .1965$ is the latest pre-Medicaid year $\left(y^{P R E}\right)$ except in panel B (1960) and the last row of panel C (1962). $\beta_{0}$ is the relationship between $A F D C_{S}^{*}$ and levels of each variable in $y^{P R E}$ (cols 2 and 5). $\beta_{1}$ is the relationship between $A F D C_{S}^{*}$ and linear trends in each variable (cols 3 and 6). Appendix figure 2.B1 plots the unrestricted annual coefficients for every pre-Medicaid year. Sources: DHHS/NCHS Multiple Cause of Death Files (1959-1965); Vital Statistics of the US (1950-1965); Haines and ICPSR (2005); SEER (2009); 1950 and 1960 Census Integrated Public Use Microsample (Ruggles et al. 2010), DHEW (2011); American Hospital Association (1950-1965); Health Insurance Institute (1952, 1954-1965); Sylla, Legler and Wallis (1993). 
Table 2. First-Stage Estimates: The Relationship between Initial AFDC Rates and Children's Public Insurance Use
(1)
(2)
(3)
(4)
(5)

Dependent Variable is Share

of Children Who Used Public

Insurance by Type of Service:

Any Hospital Doctor Drugs Dental

A. Grouped Event-Study Estimates

\section{Pre-Medicaid}

\begin{tabular}{|c|c|c|c|c|c|}
\hline (Years -3 to -2 ) $\times A F D C_{s}^{*}$ & $\begin{array}{c}0.45 \\
{[0.55]}\end{array}$ & $\begin{array}{l}-0.002 \\
{[0.06]}\end{array}$ & $\begin{array}{c}0.01 \\
{[0.22]}\end{array}$ & $\begin{array}{c}0.33 \\
{[0.3]}\end{array}$ & $\begin{array}{c}0.02 \\
{[0.17]}\end{array}$ \\
\hline \multicolumn{6}{|l|}{ Post-Medicaid } \\
\hline \multirow{2}{*}{$($ Year 0$) \times A F D C_{s}^{*}$} & 4.09 & 0.42 & 2.11 & 2.39 & 0.72 \\
\hline & [1.21] & {$[0.1]$} & {$[0.52]$} & {$[0.57]$} & {$[0.36]$} \\
\hline \multirow[t]{2}{*}{ (Years 1 to 4$) \times A F D C_{s}^{*}$} & 4.60 & 0.34 & 2.65 & 3.06 & 1.06 \\
\hline & [1.3] & {$[0.13]$} & {$[0.65]$} & [0.69] & {$[0.37]$} \\
\hline \multirow[t]{2}{*}{ (Years 5 to 6$) \times A F D C_{S}^{*}$} & 4.14 & 0.44 & 2.10 & 2.19 & 0.86 \\
\hline & [1.33] & {$[0.11]$} & {$[0.72]$} & {$[0.88]$} & {$[0.4]$} \\
\hline DD Test ( $p$-value) & 0.41 & 0.78 & 0.23 & 0.05 & 0.29 \\
\hline
\end{tabular}

\begin{tabular}{lccccc} 
Post-Medicaid $\times A F D C_{S}^{*}$ & 3.98 & 0.38 & 2.35 & 2.44 & 0.86 \\
& {$[1.01]$} & {$[0.09]$} & {$[0.49]$} & {$[0.52]$} & {$[0.28]$} \\
Bootstrap $p$-value & $(0.003)$ & $(0.002)$ & $(0.001)$ & $(0.001)$ & $(0.020)$ \\
\hline Post-Medicaid Utilization & 10.40 & 1.09 & 7.00 & 5.61 & 2.16 \\
\hline
\end{tabular}

Notes: Panel A presents estimated coefficients on the interaction between groups of time-to-Medicaid dummies (1\{t- $t_{s}^{*} \in$ $[a, b]\})$ and the initial AFDC rate $\left(A F D C_{s}^{*}\right)$. The model includes per-capita hospitals and hospital beds, per-capita income, and state, region-by-year, and Medicaid-timing-by-year fixed effects. Estimates are weighted by state populations. The public insurance data measure the share of all children 0-19 (not measured by race) who used medical services paid for by a meanstested public insurance program from 1963-1976. The earliest balanced event-year is 3 years before Medicaid began, but the estimates are not sensitive to imposing a value of zero before 1950, the first year federal cost sharing in welfare recipients' medical costs was authorized (see appendix figure 2.B3). The estimates are normalized to zero in the year before Medicaid implementation. Both $A F D C_{s}^{*}$ and public insurance utilization rates range from 0-100, so the coefficients give the effect in percentage points of a one percentage point difference in initial AFDC-based Medicaid eligibility. Standard errors clustered by state are in brackets. The row labeled "DD Test" contains the $p$-value from an $F$-test of the constant-coefficient difference-indifferences restrictions: the pre-Medicaid coefficient is zero and post-Medicaid coefficients (not including year zero) are equal to each other. The estimates of this specification are presented in panel $\mathrm{B}$. The (Years -3 to -2$) \times A F D C_{s}^{*}$ variable is omitted, (Year $0) \times A F D C_{s}^{*}$ is included (but not shown), and Post-Medicaid $\times A F D C_{s}^{*}$ refers to all event-years between 1 and 6. $p$-values from 1,000 draws of a wild-cluster bootstrap percentile-t procedure are in parentheses in panel B (Cameron et al. 2008). The sample includes 645 state-year observations that have non-missing values for public insurance use between 1963 and 1976, except West Virginia (which, prior to Medicaid, reports numbers of recipients for whom premiums into a pooled medical fund were paid as opposed to actual utilization). Sources: DHEW (various years), Haines and ICPSR (2005), SEER (2009). 


\title{
Table 3. Reduced Form Estimates: The Relationship between Initial AFDC Rates and Log
} Nonwhite Age-Adjusted Child Mortality by Specification, Coefficients $\times 100$

\author{
(1) (2)
}

(3)

(4)

(5)

(6)

\section{A. Grouped Event-Study Estimates}

\section{Pre-Medicaid}

$\begin{array}{ccccccc}\text { (Years }-16 \text { to }-12) \times A F D C_{s}^{*} & -0.11 & -0.006 & -0.65 & 0.83 & 0.28 & 1.12 \\ & {[0.37]} & {[0.69]} & {[0.67]} & {[0.72]} & {[0.77]} & {[0.99]} \\ \text { Years }-11 \text { to }-8) \times A F D C_{s}^{*} & -0.02 & -0.008 & -0.28 & 0.47 & 0.11 & -0.15 \\ & {[0.28]} & {[0.4]} & {[0.52]} & {[0.46]} & {[0.44]} & {[0.85]} \\ \text { (Years }-7 \text { to }-2) \times A F D C_{s}^{*} & 0.07 & 0.17 & -0.21 & 0.34 & 0.04 & -0.60 \\ & {[0.25]} & {[0.24]} & {[0.39]} & {[0.26]} & {[0.28]} & {[0.69]}\end{array}$

Post-Medicaid

\begin{tabular}{|c|c|c|c|c|c|c|}
\hline \multirow{2}{*}{$($ Year 0$) \times A F D C_{s}^{*}$} & -0.07 & -0.82 & -0.53 & -0.84 & -1.06 & -1.13 \\
\hline & {$[0.2]$} & {$[0.25]$} & [1.1] & {$[0.26]$} & {$[0.43]$} & {$[0.42]$} \\
\hline \multirow[t]{2}{*}{ (Years 1 to 4$) \times A F D C_{s}^{*}$} & -0.67 & -1.07 & -1.64 & -1.21 & -1.14 & -1.50 \\
\hline & {$[0.22]$} & {$[0.34]$} & {$[0.56]$} & {$[0.4]$} & {$[0.4]$} & {$[0.48]$} \\
\hline \multirow{2}{*}{ (Years 5 to 9$) \times A F D C_{s}^{*}$} & -0.82 & -1.59 & -1.58 & -1.88 & -1.78 & -1.45 \\
\hline & [0.35] & {$[0.51]$} & {$[0.51]$} & {$[0.69]$} & {$[0.49]$} & {$[0.81]$} \\
\hline $\mathrm{R}^{2}$ & 0.78 & 0.96 & 0.86 & 0.97 & 1.00 & 0.95 \\
\hline \multirow[t]{2}{*}{ DD Test ( $p$-value) } & 0.80 & 0.20 & 0.90 & 0.28 & 0.98 & 0.05 \\
\hline & \multicolumn{6}{|c|}{ B. Difference-in-Differences Estimates } \\
\hline \multirow[t]{2}{*}{ Post-Medicaid $\times A F D C_{s}^{*}$} & -0.75 & -1.41 & -1.27 & -1.26 & -1.57 & -1.46 \\
\hline & {$[0.24]$} & {$[0.34]$} & {$[0.43]$} & {$[0.51]$} & {$[0.47]$} & {$[0.40]$} \\
\hline Bootstrap $p$-value & $(0.05)$ & $(0.003)$ & $(0.001)$ & $(0.02)$ & $(0.001)$ & $(0.017)$ \\
\hline $\mathrm{R}^{2}$ & 0.78 & 0.96 & 0.86 & 0.97 & 1.00 & 0.96 \\
\hline Observations & 1,418 & 1,418 & 1,350 & 1,418 & 2,828 & 1,407 \\
\hline Covariates & $\begin{array}{c}\text { High- } \\
\text { AFDC } \\
\text { FE, } \\
\text { Time-to- } \\
\text { Medicaid } \\
\text { Dummies }\end{array}$ & $\begin{array}{c}\text { (1) + State } \\
\text { FE, } \\
\text { Medicaid- } \\
\text { timing-by- } \\
\text { year FE, } \\
\text { region-by- } \\
\text { year FE, } \\
\mathrm{X}_{\mathrm{st}}\end{array}$ & $\begin{array}{c}\text { (2), } \\
\text { unweighted }\end{array}$ & $\begin{array}{l}(2)+ \\
\text { state- } \\
\text { specific } \\
\text { linear } \\
\text { trends }\end{array}$ & $\begin{array}{c}\text { Pooled } \\
\text { Races, } \\
\text { (2)*Nonwhite } \\
\text { + state-by- } \\
\text { year FE }\end{array}$ & $\begin{array}{c}\text { (2), IV } \\
\text { using } \\
1958 \\
\text { AFDC } \\
\text { Rates }\end{array}$ \\
\hline \multicolumn{3}{|l|}{ Mortality Rate in $t^{*}-1$} & 391.5 death & per 100,0 & & \\
\hline \multicolumn{7}{|c|}{$\begin{array}{l}\text { Notes: Panel A presents estimated coefficients on the interaction between groups of time-to-Medicaid dummies }\left(1\left\{t-t_{s}^{*} \in\right.\right. \\
[a, b]\}) \text { and the continuous value of initial AFDC rates. The estimates are multiplied by } 100 \text { to represent the effect in log points } \\
\text { of a one percentage point difference in initial AFDC rates. Standard errors clustered by state are in brackets. The estimates are } \\
\text { normalized to zero in the year before Medicaid implementation. Arizona is excluded because it implemented Medicaid in 1982, } \\
\text { Alaska and Hawaii are excluded because they are not measured in Vital Statistics data before 1959. New Jersey did not report } \\
\text { race codes in } 1962 \text { and } 1963 \text {, so I allocate total deaths by race using interpolated race share of deaths. Column } 3 \text { omits the } \\
\text { smallest nonwhite states: Maine, New Hampshire, and Vermont. The row labeled "DD Test" contains the } p \text {-value from an F-test } \\
\text { of the constant-coefficient difference-in-differences restrictions: the pre-Medicaid coefficients are jointly zero and post-Medicaid } \\
\text { coefficients (not including year zero) are equal to each other. DD estimates are shown in panel B. A Hausman test does not reject } \\
\text { the null hypothesis that weighted and unweighted estimates are equal for either the grouped event-study model }(p \text {-value }=0.50) \\
\text { or the DD model ( } p \text {-value }=0.90 \text { ) (Deaton } 1997 \text {; Solon, Haider and Wooldridge 2015). } p \text {-values from } 1,000 \text { draws of a wild- } \\
\text { cluster bootstrap percentile- } t \text { procedure are in parentheses in panel B (Cameron et al. 2008). Sources: see notes to figure } 6 \text {. }\end{array}$} \\
\hline
\end{tabular}


Table 4. The Relationship between Initial AFDC Rates and Log Nonwhite Infant Mortality by Age at Death, Coefficients $\times 100$

Dependent Variable is the
log Mortality Rate During:

Pre-Medicaid

(Years -16 to -12$) \times A F D C_{S}^{*}$

(Years -11 to -8$) \times A F D C_{s}^{*}$

(Years -7 to -2$) \times A F D C_{S}^{*}$

Post-Medicaid
$(1)$

(2)

Day 1
(3)

Days 2-27

Neonatal Period
(before 28 days)

(4)

Post-Neonatal

Period (28 days

to 1 year)

First Year

A. Grouped Event-Study Estimates

\begin{tabular}{|c|c|c|c|c|c|}
\hline \multirow[t]{2}{*}{ (Years -16 to -12 ) $\times A F D C_{s}^{*}$} & 0.16 & 0.85 & 0.31 & 2.02 & 1.00 \\
\hline & {$[0.67]$} & {$[1.29]$} & {$[0.73]$} & {$[1.03]$} & {$[0.73]$} \\
\hline \multirow[t]{2}{*}{ (Years -11 to -8 ) $\times A F D C_{s}^{*}$} & -0.10 & 1.47 & 0.37 & 1.22 & 0.72 \\
\hline & {$[0.51]$} & {$[1.18]$} & {$[0.55]$} & {$[0.85]$} & {$[0.50]$} \\
\hline \multirow[t]{2}{*}{ (Years -7 to -2 ) $\times A F D C_{s}^{*}$} & -0.09 & 0.47 & 0.08 & 0.75 & 0.35 \\
\hline & {$[0.44]$} & {$[0.92]$} & {$[0.45]$} & {$[0.52]$} & {$[0.26]$} \\
\hline \multicolumn{6}{|l|}{ Post-Medicaid } \\
\hline \multirow[t]{2}{*}{$($ Year 0$) \times A F D C_{s}^{*}$} & -0.79 & -0.76 & -0.71 & 0.18 & -0.26 \\
\hline & {$[0.48]$} & {$[1.19]$} & {$[0.52]$} & {$[0.59]$} & {$[0.30]$} \\
\hline \multirow[t]{2}{*}{ (Years 1 to 4$) \times A F D C_{s}^{*}$} & -1.39 & -0.77 & -1.15 & -0.14 & -0.73 \\
\hline & {$[0.57]$} & {$[0.77]$} & {$[0.47]$} & {$[0.46]$} & {$[0.30]$} \\
\hline \multirow[t]{2}{*}{$($ Years 5 to 9$) \times A F D C_{S}^{*}$} & -1.63 & -0.92 & -1.37 & -0.49 & -0.99 \\
\hline & {$[0.61]$} & {$[1.10]$} & {$[0.51]$} & {$[0.83]$} & {$[0.40]$} \\
\hline \multirow[t]{2}{*}{ DD Test ( $p$-value) } & 0.93 & 0.57 & 0.53 & 0.05 & 0.31 \\
\hline & \multicolumn{5}{|c|}{ B. Difference-in-Differences Estimates } \\
\hline \multirow[t]{2}{*}{ Post-Medicaid $\times A F D C_{S}^{*}$} & -1.50 & -1.61 & -1.47 & -1.44 & -1.44 \\
\hline & {$[0.47]$} & {$[0.86]$} & {$[0.40]$} & {$[0.63]$} & {$[0.44]$} \\
\hline Bootstrap $p$-value & $(0.02)$ & $(0.12)$ & $(0.01)$ & $(0.05)$ & $(0.01)$ \\
\hline \multirow[t]{2}{*}{ Contribution to IMR Effect } & $49 \%$ & $21 \%$ & $68 \%$ & $34 \%$ & $100 \%$ \\
\hline & \multicolumn{5}{|c|}{ C. Difference-in-Differences Estimates w/ Birth Weight Controls } \\
\hline \multirow[t]{2}{*}{ Post-Medicaid $\times A F D C_{S}^{*}$} & -1.27 & -1.57 & -1.31 & -1.44 & -1.33 \\
\hline & {$[0.43]$} & {$[0.87]$} & {$[0.40]$} & {$[0.59]$} & {$[0.42]$} \\
\hline Bootstrap $p$-value & $(0.03)$ & $(0.13)$ & $(0.02)$ & $(0.03)$ & $(0.02)$ \\
\hline Contribution to IMR Effect & $45 \%$ & $22 \%$ & $65 \%$ & $37 \%$ & $100 \%$ \\
\hline Observations & 1,395 & 1,361 & 1,405 & 1,387 & 1,417 \\
\hline Rate in $t^{*}-1$ & 17.8 & 7.1 & 24.9 & 12.7 & 37.6 \\
\hline $\begin{array}{l}\text { Notes: Panels A and B are str } \\
\text { rates (cf. Currie and Gruber } 1 \\
\text { mortality accounted for by ea } \\
\text { t*-1 (which is approximately } \\
\text { column 5. Sources: see notes }\end{array}$ & 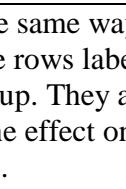 & 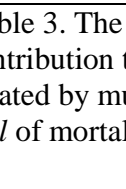 & $\begin{array}{l}\text { anel C } \\
\text { ect" sho }\end{array}$ & $\begin{array}{l}\text { Dw and } \\
\text { of the } t \\
\text { ded by }\end{array}$ & $\begin{array}{l}\text { irth weigh } \\
\text { on infant } \\
\text { e level in } \\
\text { es from }\end{array}$ \\
\hline
\end{tabular}


Table 5. The Relationship between Initial AFDC Rates and Nonwhite Health at Birth, Coefficients $\times 100$

(1)

\begin{tabular}{|c|c|c|c|c|}
\hline \multirow[t]{2}{*}{ Dependent Variable: } & $\begin{array}{c}\text { log Very Low } \\
\text { Birth Weight } \\
(<1,500 \text { grams })\end{array}$ & $\begin{array}{l}\log \text { Low Birth } \\
\text { Weight } \\
(<2,500 \text { grams })\end{array}$ & $\begin{array}{l}\text { Male-to-Female } \\
\text { Sex Ratio at Birth }\end{array}$ & $\begin{array}{l}\text { Maternal } \\
\text { Mortality }\end{array}$ \\
\hline & \multicolumn{4}{|c|}{ A. Grouped Event-Study Estimates } \\
\hline \multirow{3}{*}{$\begin{array}{l}\text { Pre-Medicaid } \\
\quad \text { (Years }-16 \text { to }-12) \times A F D C_{s}^{*}\end{array}$} & & & & \\
\hline & -0.21 & 0.55 & 0.07 & \\
\hline & {$[0.76]$} & [0.33] & [0.13] & \\
\hline \multirow{2}{*}{ (Years -11 to -8$) \times A F D C_{s}^{*}$} & -0.22 & 0.61 & -0.13 & \\
\hline & [0.61] & {$[0.26]$} & {$[0.11]$} & \\
\hline \multirow[t]{2}{*}{ (Years -7 to -2$) \times A F D C_{s}^{*}$} & -0.90 & 0.20 & 0.07 & 0.13 \\
\hline & [0.53] & {$[0.20]$} & [0.13] & {$[0.18]$} \\
\hline \multicolumn{5}{|l|}{ Post-Medicaid } \\
\hline \multirow[t]{2}{*}{$($ Year 0$) \times A F D C_{s}^{*}$} & -1.02 & -0.07 & 0.08 & 0.15 \\
\hline & {$[0.76]$} & [0.25] & {$[0.19]$} & {$[0.19]$} \\
\hline \multirow[t]{2}{*}{ (Years 1 to 4$) \times A F D C_{s}^{*}$} & -1.02 & 0.15 & -0.05 & -0.07 \\
\hline & {$[0.61]$} & {$[0.19]$} & {$[0.15]$} & {$[0.18]$} \\
\hline \multirow[t]{2}{*}{ (Years 5 to 9$) \times A F D C_{s}^{*}$} & -1.45 & 0.25 & 0.03 & -0.02 \\
\hline & {$[0.67]$} & {$[0.25]$} & {$[0.14]$} & {$[0.21]$} \\
\hline \multirow[t]{2}{*}{ DD Test ( $p$-value) } & 0.03 & 0.01 & 0.03 & 0.67 \\
\hline & \multicolumn{4}{|c|}{ B. Difference-in-Differences Estimates } \\
\hline \multirow[t]{2}{*}{ Post-Medicaid $\times A F D C_{s}^{*}$} & -0.75 & -0.17 & -0.02 & -0.16 \\
\hline & {$[0.44]$} & {$[0.3]$} & {$[0.07]$} & {$[0.10]$} \\
\hline Bootstrap $p$-value & $(0.12)$ & $(0.63)$ & $(0.76)$ & $(0.12)$ \\
\hline Observations & 1,327 & 1,369 & 1,438 & 1,008 \\
\hline Rate in $t^{*}-1$ & 23.6 & 138.5 & 1.03 & 7.35 \\
\hline
\end{tabular}

Notes: For details on the specification and sources see notes to table 3. Columns 1 and 2 present coefficients from regressions of the log birth weight variables. Connecticut and Massachusetts are dropped because they did not report birth weight before 1958. Column 3 presents coefficients from a regression of the ratio of male to female births (higher values indicate better infant health since male fetuses are weaker than female fetuses). Column 4 presents coefficients from a regression of the level of age-adjsuted maternal mortality using data starting in 1959. Coefficients in columns 1-3 are multiplied by 100. 
Table 6. The Relationship between Initial AFDC Rates and Nonwhite Birth Outcomes by Mother's AFDC Eligibility, 1965-1972, Coefficients $\times 100$

\begin{tabular}{|c|c|c|c|}
\hline & (1) & $(2)$ & (3) \\
\hline Dependent Variable: & $\begin{array}{l}\text { Born in an } \\
\text { Institution }\end{array}$ & $\begin{array}{l}\text { Low Birth Weight } \\
\text { (Birth Weight } \\
<2500 \text { grams) }\end{array}$ & $\begin{array}{c}\text { Premature } \\
\text { (Gestation }<36 \\
\text { Weeks) }\end{array}$ \\
\hline \multicolumn{4}{|l|}{ Post-Medicaid $\times A F D C_{S}^{*}$} \\
\hline & \multicolumn{3}{|c|}{ Potentially Medicaid-Eligible Mothers } \\
\hline \multirow[t]{2}{*}{ Poor } & 0.62 & -0.14 & -0.06 \\
\hline & [0.32] & {$[0.54]$} & {$[0.44]$} \\
\hline \multirow[t]{3}{*}{ Non-Poor } & 0.22 & 0.27 & 0.55 \\
\hline & {$[0.26]$} & {$[0.84]$} & {$[0.58]$} \\
\hline & \multicolumn{3}{|c|}{ Medicaid Ineligible Mothers } \\
\hline \multirow[t]{2}{*}{ Poor } & 0.19 & 0.03 & 0.34 \\
\hline & {$[0.30]$} & [1.01] & [0.89] \\
\hline \multirow[t]{2}{*}{ Non-Poor } & 0.12 & -0.04 & 0.12 \\
\hline & {$[0.20]$} & {$[0.69]$} & {$[0.50]$} \\
\hline Observations & 3,944 & 3,944 & 3,746 \\
\hline $\begin{array}{l}\text { Mean Dependent Variable for } \\
\text { Poor Mothers before Medicaid }\end{array}$ & 88.2 & 12.2 & 7.8 \\
\hline
\end{tabular}

Notes: The table contains estimated coefficients (multiplied by 100) from a linear probability model that includes triple-interactions between a dummy that equals one for all years after (but not including) the year of Medicaid implementation, $A F D C_{s}^{*}$, and indicators for whether mothers' income was below 150 percent of the poverty line and whether the birth was potentially eligible for Medicaid. Most states (34) excluded first-time pregnant women from AFDC and, therefore, Medicaid. The definition of "Medicaid Eligible” in these results is a subsequent birth or a first birth in a state that provided AFDC to first-time pregnant mothers. The model also includes state fixed effects, separate year fixed effects for each Medicaid timing group, region-by-year fixed effects and dummies for 10 bins of family income interacted with year dummies, dummies for each year of the mother's age, an indicator for the sex of the child, and an indicator for plural births. Standard errors clustered at the state level are in brackets. The regressions are weighted by the sampling weights. Source: National Natality Followback Surveys 1964-1966 and 1972, National Natality Surveys 1967-1969. 
Table 7. The Relationship between Initial AFDC Rates and Log Nonwhite Child Mortality by Age and Cause, Coefficients $\times 100$

\begin{tabular}{|c|c|c|c|c|c|c|c|}
\hline & $(1)$ & $(2)$ & $(3)$ & $(4)$ & (5) & $(6)$ & $(7)$ \\
\hline \multirow[t]{2}{*}{$\begin{array}{l}\text { Dependent Variable is the } \\
\text { log Mortality Rate for: }\end{array}$} & Ages 1-4 & Ages 5-9 & Ages 10-14 & $\begin{array}{l}\text { Internal Causes, } \\
\text { Ages 1-14 }\end{array}$ & $\begin{array}{l}\text { External } \\
\text { Causes, } \\
\text { Ages 1-14 }\end{array}$ & $\begin{array}{l}\text { Treatable } \\
\text { Causes, } \\
\text { Ages 1-14 }\end{array}$ & $\begin{array}{l}\text { Untreatable } \\
\text { Causes, } \\
\text { Ages 1-14 }\end{array}$ \\
\hline & \multicolumn{7}{|c|}{ A. Grouped Event-Study Estimates } \\
\hline \multirow{3}{*}{$\begin{array}{l}\text { Pre-Medicaid } \\
\text { (Years }-16 \text { to }-12) \times A F D C_{S}^{*}\end{array}$} & & & & & & & \\
\hline & -0.75 & 0.17 & -1.31 & -0.34 & -0.96 & & \\
\hline & {$[0.92]$} & {$[0.86]$} & {$[1.1]$} & {$[0.88]$} & {$[0.79]$} & & \\
\hline \multirow[t]{2}{*}{ (Years -11 to -8$) \times A F D C_{s}^{*}$} & -0.41 & 0.80 & -0.47 & 0.11 & -0.25 & & \\
\hline & {$[0.89]$} & {$[0.73]$} & {$[1.05]$} & {$[0.66]$} & {$[0.88]$} & & \\
\hline \multirow[t]{2}{*}{ (Years -7 to -2 ) $\times A F D C_{S}^{*}$} & -0.77 & 0.75 & -0.34 & -0.15 & -0.31 & -0.35 & 0.73 \\
\hline & {$[0.72]$} & {$[0.71]$} & [0.99] & {$[0.77]$} & {$[0.87]$} & {$[0.89]$} & {$[1.37]$} \\
\hline \multicolumn{8}{|l|}{ Post-Medicaid } \\
\hline \multirow[t]{2}{*}{$($ Year 0$) \times A F D C_{s}^{*}$} & -1.90 & -1.38 & -1.27 & -1.05 & -2.04 & -1.22 & -0.61 \\
\hline & {$[1.06]$} & {$[0.96]$} & [1.29] & {$[0.85]$} & {$[0.97]$} & [0.93] & [1.58] \\
\hline \multirow[t]{2}{*}{ (Years 1 to 4$) \times A F D C_{S}^{*}$} & -2.27 & 0.11 & -0.57 & -1.67 & -0.90 & -1.85 & -0.63 \\
\hline & {$[0.72]$} & {$[0.82]$} & [1.05] & {$[0.68]$} & {$[0.71]$} & {$[0.78]$} & [1.08] \\
\hline \multirow[t]{2}{*}{ (Years 5 to 9$) \times A F D C_{s}^{*}$} & -3.38 & -0.02 & -0.77 & -2.33 & -1.83 & -3.11 & -0.30 \\
\hline & {$[0.93]$} & {$[0.91]$} & [1.12] & {$[0.72]$} & {$[0.98]$} & {$[0.78]$} & [1.11] \\
\hline \multirow[t]{2}{*}{ DD Test ( $p$-value) } & 0.25 & 0.53 & 0.56 & 0.68 & 0.53 & 0.06 & 0.85 \\
\hline & \multicolumn{7}{|c|}{ B. Difference-in-Differences Estimates } \\
\hline \multirow[t]{2}{*}{ Post-Medicaid $\times A F D C_{S}^{*}$} & -2.23 & -0.51 & -0.13 & -1.88 & -0.96 & -2.16 & -1.09 \\
\hline & {$[0.55]$} & {$[0.40]$} & {$[0.56]$} & {$[0.41]$} & {$[0.55]$} & {$[0.51]$} & {$[0.80]$} \\
\hline Bootstrap $p$-value & $(0.001)$ & $(0.20)$ & $(0.83)$ & $(0.002)$ & $(0.12)$ & $(0.001)$ & $(0.28)$ \\
\hline Observations & 1,362 & 1,305 & 1,279 & 1,349 & 1,357 & 929 & 849 \\
\hline Rate in $t^{*}-1$ & 153.5 & 58.5 & 55.1 & 48.0 & 39.2 & 35.7 & 12.3 \\
\hline
\end{tabular}

Notes: For details on the specification and sources see notes to table 3. Columns 1 - 3 contain estimates for the log of age-group-specific mortality rates for nonwhite children. Columns 4 and 5 contain estimates for the log of age-adjusted internal- and external-cause mortality rates (see notes to figure 4). Columns 6 and 7 contain estimates for the log of age-adjusted infectious- and non-infectious-disease mortality rates, which together account for the vast majority of internal-cause deaths. For the ICD codes included in these groups see appendix 1. The final row shows the average level (not log) of the dependent variable in the year prior to Medicaid implementation. Sources: See notes to figure 6. 
Table 8. The Robustness of Medicaid's Mortality Effects to Time-Varying AFDC Controls, Coefficients $\times 100$

Dependent Variable:

Treatment Effects:

Post-Medicaid $\times$ Nonwhite $A F D C_{S}^{*}$

Bootstrap $p$-value

Falsification Test:

Post-Medicaid $\times$ White $A F D C_{S}^{*}$
(1)

(2)

$\log$ Nonwhite

Mortality, Ages 0-14

log Nonwhite Neonatal

Infant Mortality

(3)

A. Controlling for White-AFDC Medicaid Timing Interactions

$\log$ Nonwhite Mortality, Ages 1-4 $\begin{array}{lll}-1.43 & -1.40 & -2.13\end{array}$

$[0.55] \quad[0.62]$

$(0.05) \quad(0.11)$
[0.78]

(0.05)

$\begin{array}{lll}0.09 & 0.06 & 0.19\end{array}$

[0.25]

[0.26]

[0.30]

B. Controlling for State-by-Year Nonwhite AFDC Rate

Post-Medicaid $\times A F D C_{S}^{*}$

$-1.23$

[0.37]

$(0.004)$
$-1.37$

[0.30]

(0.001)
$-1.59$

Bootstrap $p$-value

Notes: The table contains estimates from two specification tests. Panel A presents coefficients on interactions between a postMedicaid dummy and nonwhite $A F D C_{S}^{*}$ (treatment effects) and white $A F D C_{S}^{*}$ (falsification test). The estimated treatment effects for nonwhite mortality are robust to the inclusion controls for white AFDC rates before and after Medicaid implementation. Panel $B$ presents estimated coefficients on interactions between post-Medicaid dummy and an indicator for high-nonwhite-AFDC states as in equation (1). The regressions also includes state-by-year nonwhite welfare rates $\left(A F D C_{s t}\right)$ and their interaction with a post1966 dummy $\left(A F D C_{s t} \cdot 1\{y \geq 1966\}\right)$. These controls account for omitted factors that are correlated with levels and changes in specifically nonwhite AFDC rates, and any change in the relationship between these factors on mortality in the mid-1960s. The results show that the estimated treatment effects of Medicaid in high-nonwhite-AFDC states are robust to controls for AFDC rates themselves. Source: see notes to table 3. 


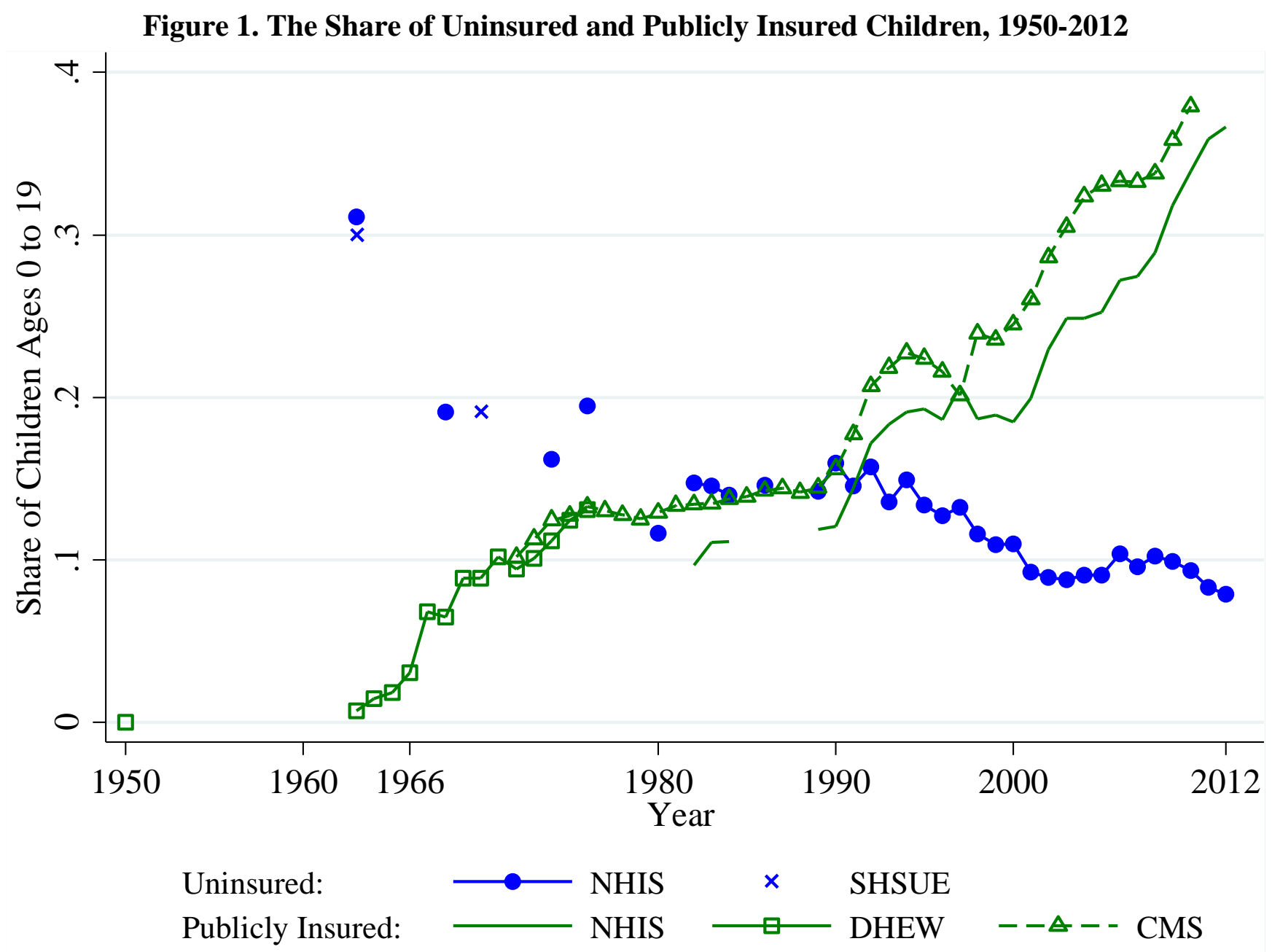

Notes: The figure plots the share children ages 0 to 19 that received some form of means-tested public insurance or were uninsured from 1950 to 2012. The 1963, 1968 and 1974 data come from ICPSR National Health Interview Survey files and the 1976-2012 data come from the Integrated Health Interview Survey. NHIS/IHIS estimates of uninsurance are shown in closed blue circles, and of public insurance (including Medicaid and the State Children's Health Insurance Program) are shown in the solid line. Children are classified as having no insurance if they report no hospital insurance, surgical insurance or doctor insurance and (in 1968 and 1974) if they do not list coverage through "Medicare, Medicaid or welfare" as a reason for not having insurance (children with missing or unknown insurance status are excluded). The share of uninsured children in the SHSUE is calculated using direct questions on the number of health insurance policies. In 1970, children who report expenditures paid by "public aid (receiving welfare payments), Medicaid (receiving no welfare payments), and/or free or part pay clinic or public hospital services” are counted as insured. The open squares and triangles are based on administrative data, and show the ratio of unduplicated annual counts of Medicaid child recipients (rather than enrollees) to the population age 0 to 19. For a description of the Department of Health, Education and Welfare (DHEW) data see appendix 1. The Center for Medicare and Medicaid Services (CMS) data are from the 2012 Medicare and Medicaid Statistical Supplement Table 13.4. Population denominators are from the SEER and the 2000-2010 intercensal population estimates. This share is set to zero in 1950, when federal participation in medical costs of welfare recipients was first authorized. Sources: DHEW (various years); Center for Medicare and Medicaid Services (2012); Center for Health Administration Studies and National Opinion Research Center (1984a; 1984b); United States Department of Health and Human Services et al. (2010a; 2010b; 2010c); Minnesota Population Center and State Health Access Data Assistance Center (2012). 
Figure 2. Medicaid Categorical Eligibility: The Rate of AFDC Receipt by Age and Race, December 1967

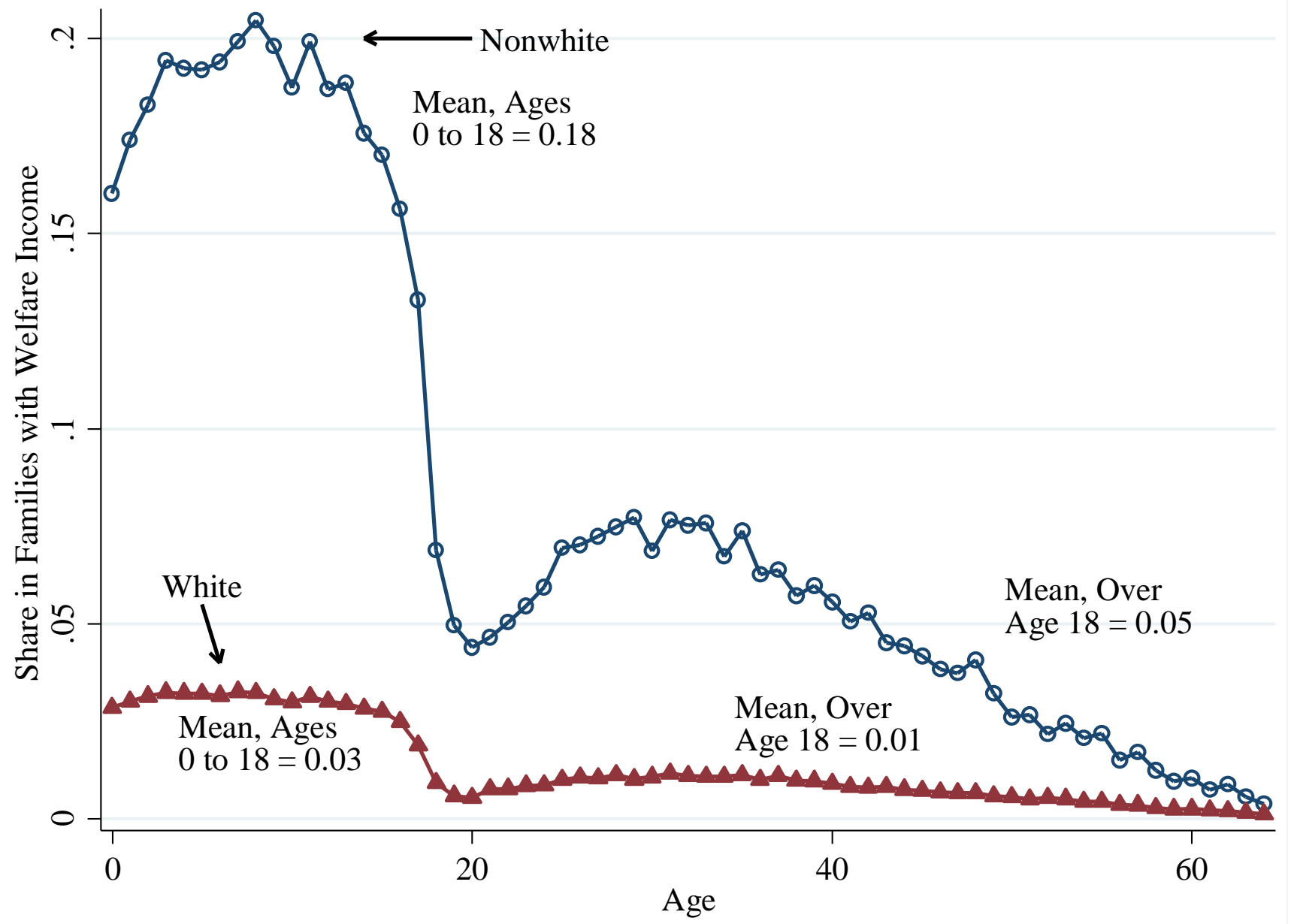

Notes: The figure plots the estimated shares of white and nonwhite people of each age who received a payment from the Aid to Families with Dependent Children (AFDC) program in December 1967. The series are constructed by calculating the joint age and race distribution of AFDC recipients using the 1967 AFDC Study, multiplying it by the total number of AFDC cases in December 1967, and dividing by inter-censal population estimates (U.S. Census Bureau 2001). AFDC receipt was the most common way that families qualified for Medicaid because of the requirement that welfare recipients be covered ("categorical eligibility"). The figure shows that categorical eligibility for Medicaid was about four times higher for children than for adults, and six times higher for nonwhite children than white children. 


\section{Figure 3. The Share of Children Using Public Health Insurance before and after Medicaid}

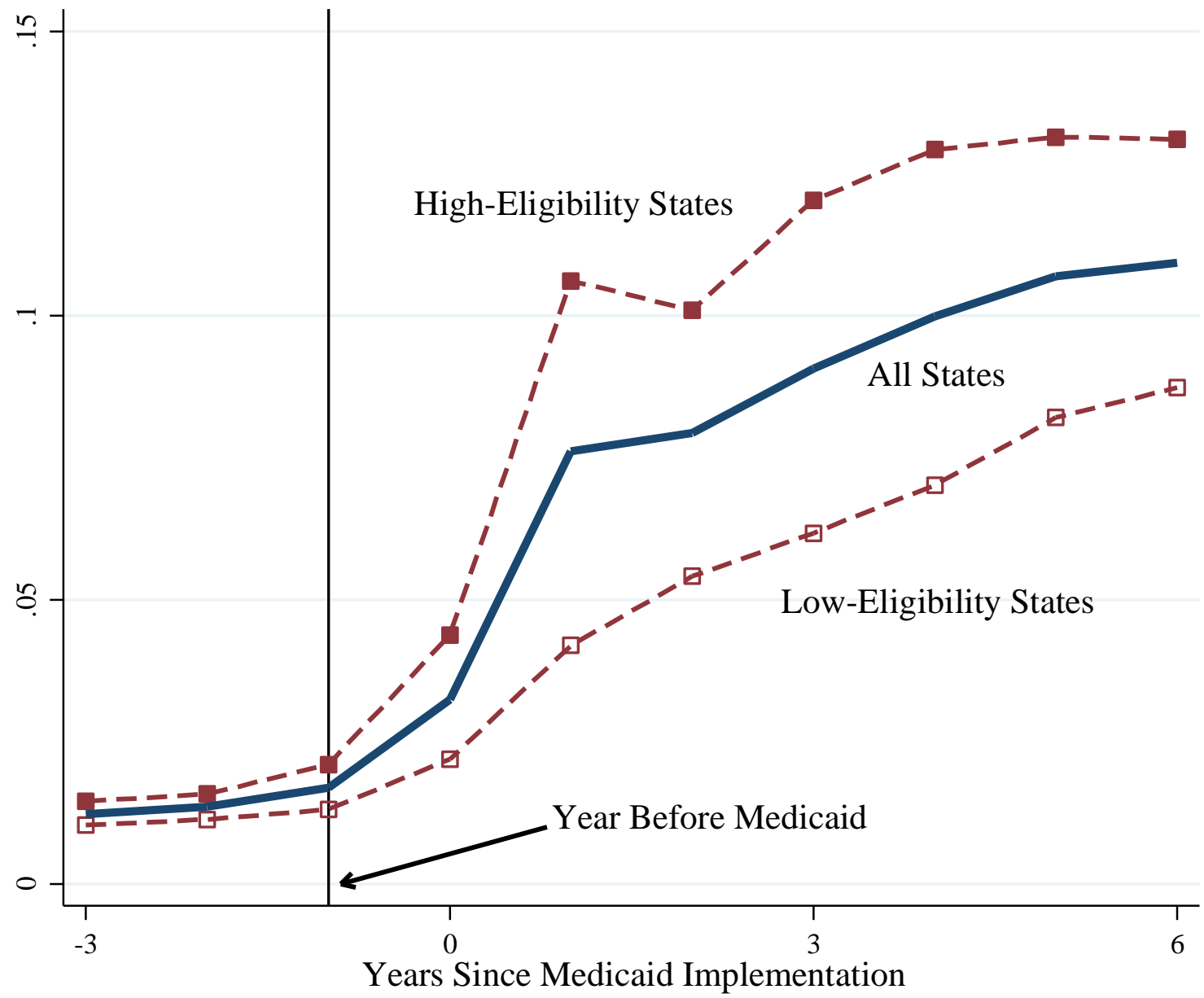

Notes: The figure plots the share of children ages 0-19 who received medical services paid for by a means-tested public insurance program in the years before and after states implemented Medicaid. High- and low-eligibility states are defined by the median value of AFDC rates in the year states implemented Medicaid $\left(A F D C_{S}^{*}\right)$. Source: AFDC cases are from Health and Human Services Caseload Data 1960-1999 (HHS 2012); population data are from 1960 population estimates (Haines and ICPSR 2005), and the Survey of Epidemiological End Results (SEER 2009); data on public insurance use are collected from various editions of "Recipients of Medical Vendor Payments Under Public Assistance Programs” and “Medicaid State Tables” (DHEW 1963-1976). Appendix 1 describes the public insurance data. 
Figure 4. Share of Deaths Due to Internal Causes by Age, 1959, 1965 and 1971

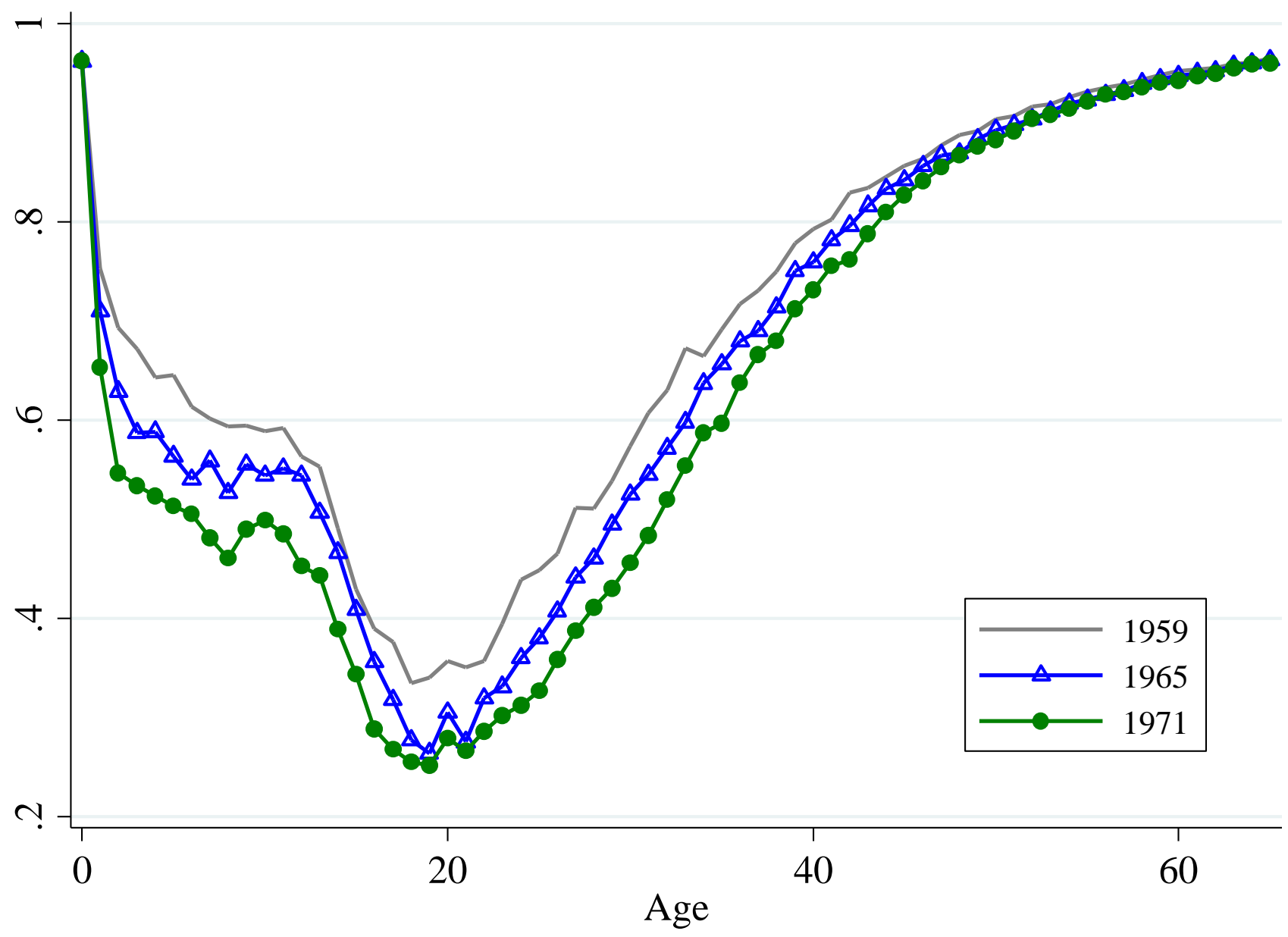

Notes: The figure plots the share of deaths at each single age due to internal causes of death. Internal causes include all deaths not due to “external” causes in the International Classification of Diseases Revision 7 (ICD7 codes E800-E999). Source: Vital Statistics MultipleCause of Death File, 1965 (US DHHS 2007). 
Figure 5. Regression-Adjusted Estimates of Medicaid's Effect on Children's Public Insurance Use

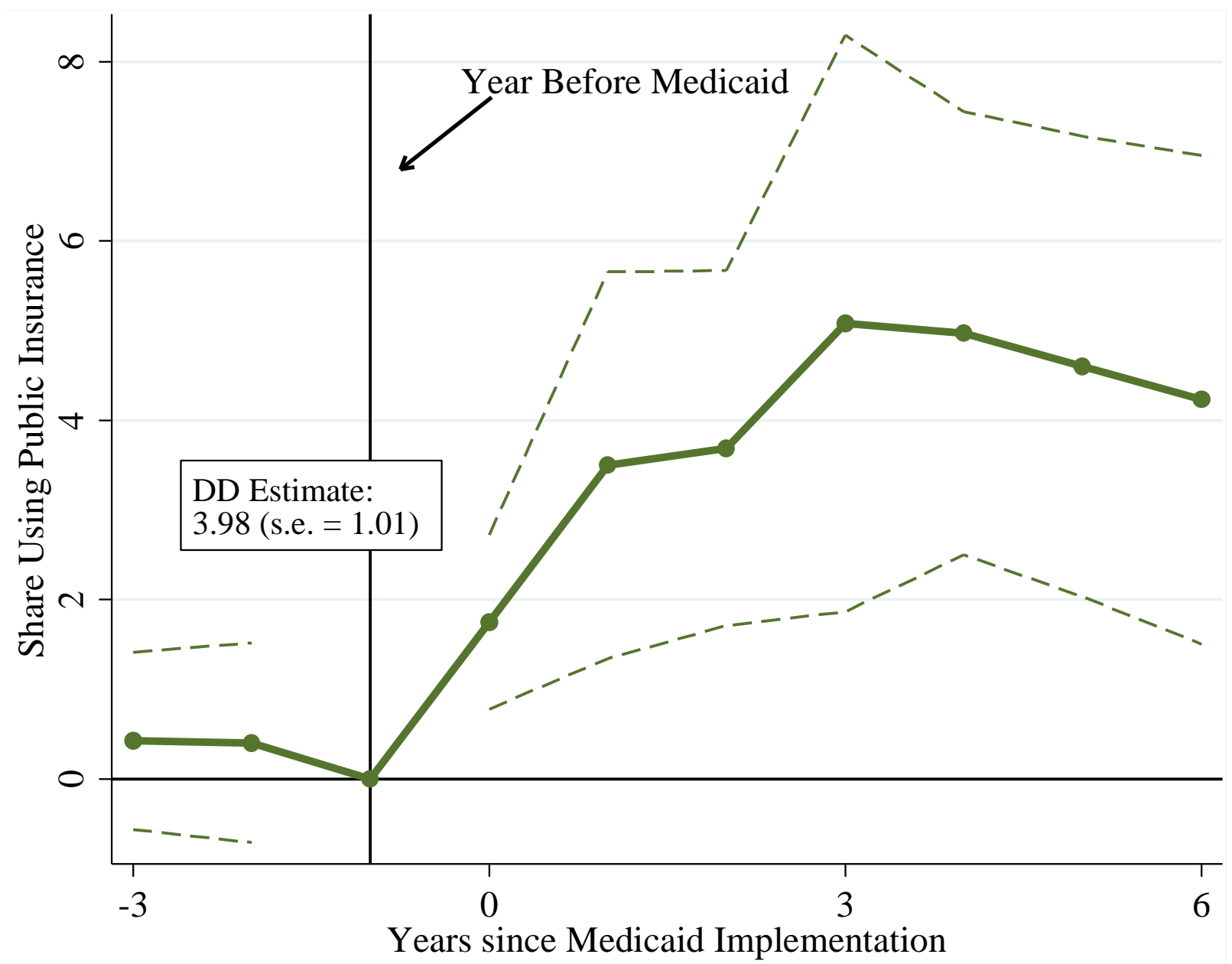

Notes: The dependent variable is the estimated share of children ages 0-19 that received services covered by a means-tested public insurance program. The figure plots the estimated coefficient on interactions between time-to-Medicaid dummies $\left(1\left\{t-t_{s}^{*}=y\right\}\right)$ and initial AFDC rates $\left(A F D C_{S}^{*}\right)$ in a regression model described in Section III. The year before Medicaid implementation is omitted so the estimates are normalized to zero in that year. The model also includes state fixed effects, per-capita income and hospital capacity variables, region-by-year fixed effects, and separate year fixed effects for each Medicaid timing group. The dashed lines are pointwise 95 percent confidence intervals based on standard errors clustered at the state level. The sample includes 645 state-year observations that have nonmissing values for public insurance use between 1963 and 1976, except West Virginia (which, prior to Medicaid, reports numbers of recipients for whom premiums into a pooled medical fund were paid as opposed to actual utilization). The estimates are weighted by state populations aged 0-19, but a Hausman test cannot reject the null hypothesis that the weighted and unweighted estimates are equal ( $p$-value = 0.54; Deaton 1997; Solon, Haider, and Wooldridge 2013). Source: See appendix 1. 


\section{Figure 6. Regression-Adjusted Estimates of Medicaid's Intention-to-Treat Effect on}

Child Mortality by Race
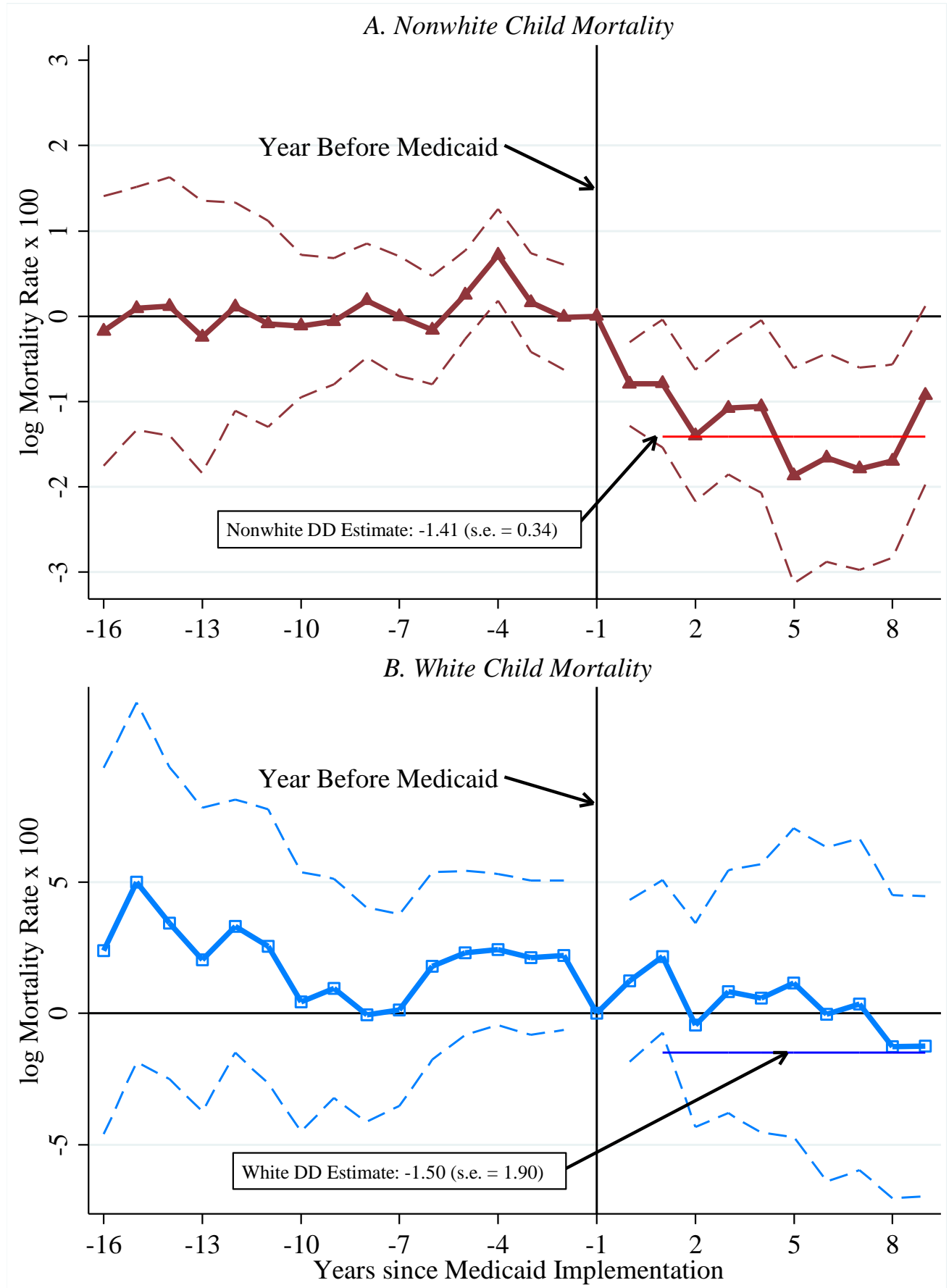

Notes: The dependent variable is the natural log of the age-adjusted mortality rate among children aged 0 -14. The figure plots the estimated coefficients on interactions between time-to-Medicaid dummies $\left(1\left\{t-t_{s}^{*}=y\right\}\right)$ and initial AFDC rates (AFDC*) from the regression model described in Section III. The year before Medicaid implementation is omitted so the estimates are normalized to zero in that year. States observed more than 16 years before Medicaid (the latest-implementing states) or more than 9 years after (the earliest implementing states) are grouped into endpoint dummies and their coefficients are not shown (McCrary 2007). Alaska, Hawaii and Arizona are omitted, and West Virginia is omitted from the white sample. The model includes state fixed effects, separate year fixed effects for each Medicaid timing group, per-capita income and hospital variables, and region-by-year fixed effects. The broken lines are pointwise 95 percent confidence intervals based on standard errors clustered at the state level. Source: Vital Statistics Multiple-Cause of Death Files 1959-1979 (US DHHS and NCHS 2009), Haines and ICPSR (2005), SEER (2009). 
Figure 7. Regression-Adjusted Estimates of Medicaid's Intention-to-Treat Effect on Nonwhite Child Mortality by Age
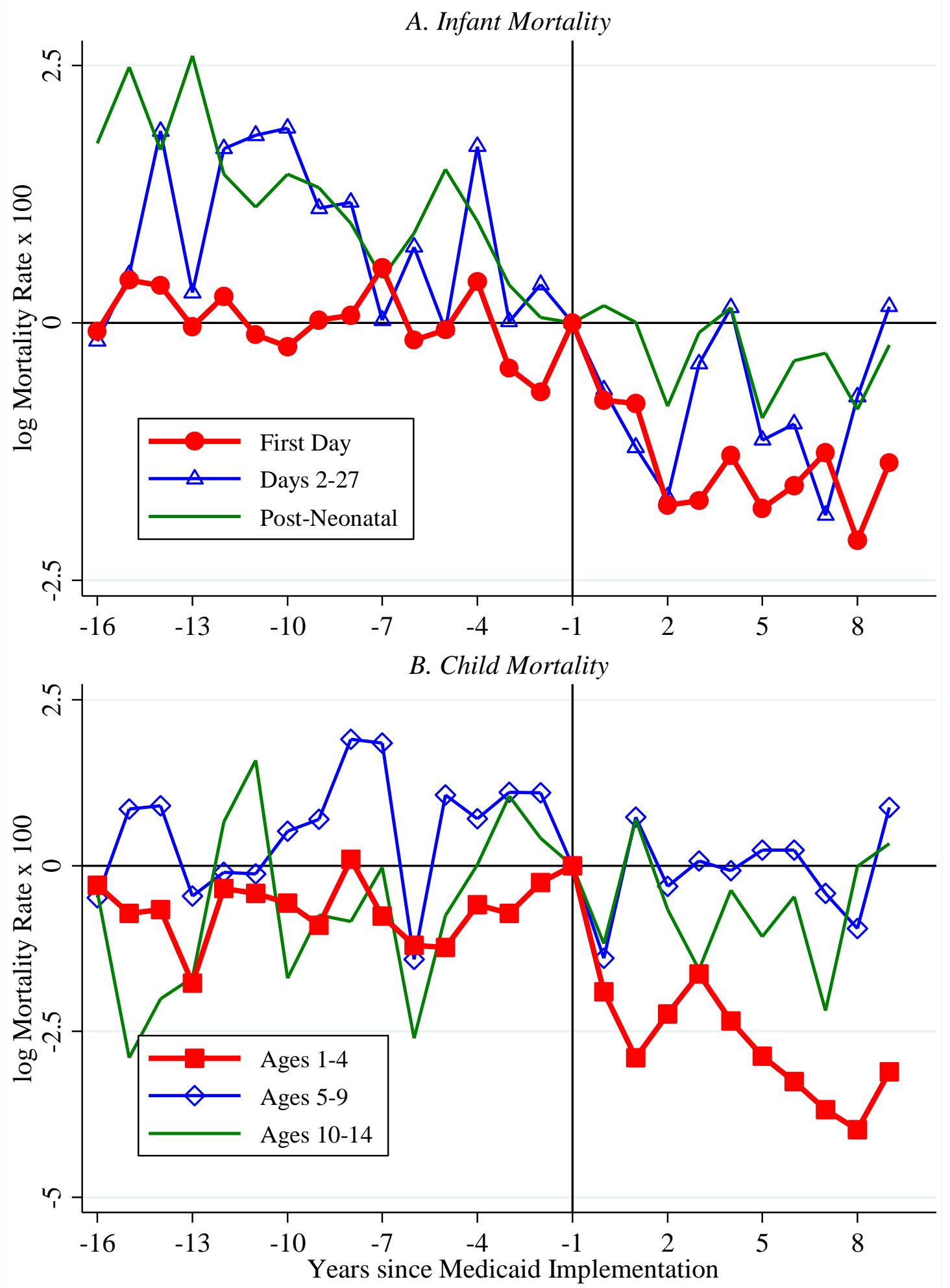

Notes: See notes to figure 6. 
Figure 8. Regression-Adjusted Estimates of Medicaid's Intention-to-Treat Effect on Cumulative

Nonwhite Infant Mortality by Hour and Day of Death

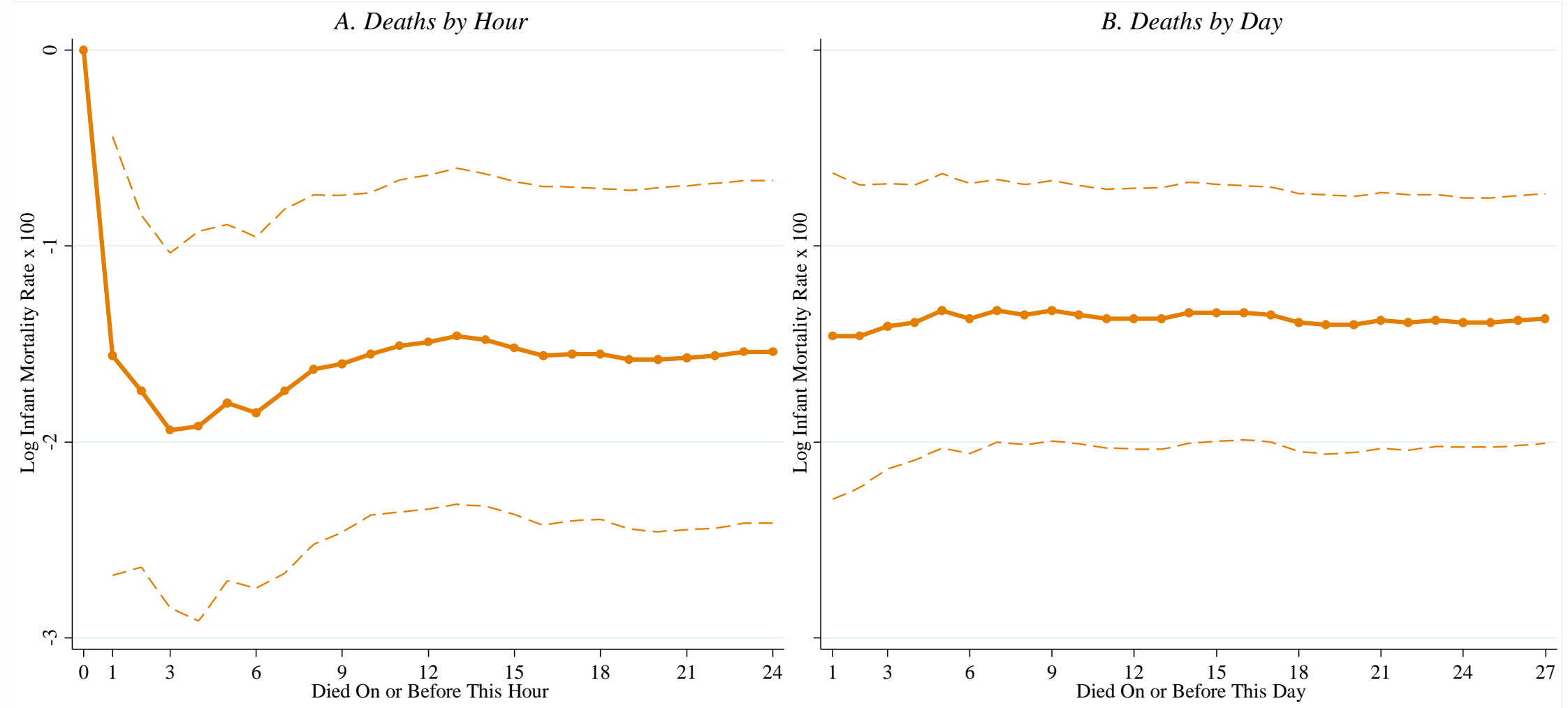

Notes: The figure plots DD estimates of Medicaid's effect on nonwhite infant mortality rates based on the same specification as in figure 6 . The dependent variable is the log of the infant

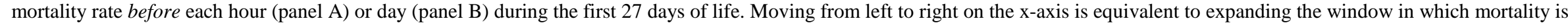
measured. The right-most estimate is therefore comparable to the effect on neonatal infant mortality rates from column 3 of table 4 . Because mortality rates are calculated conditional on being born alive, the effect at "hour zero" is normalized to zero. Data on deaths by detailed hour and day are only available beginning in 1959 . Source: see notes to figure 6 and table 4. 


\section{Figure 9. The Relationship between Medicaid Implementation and Health-Related Programs}

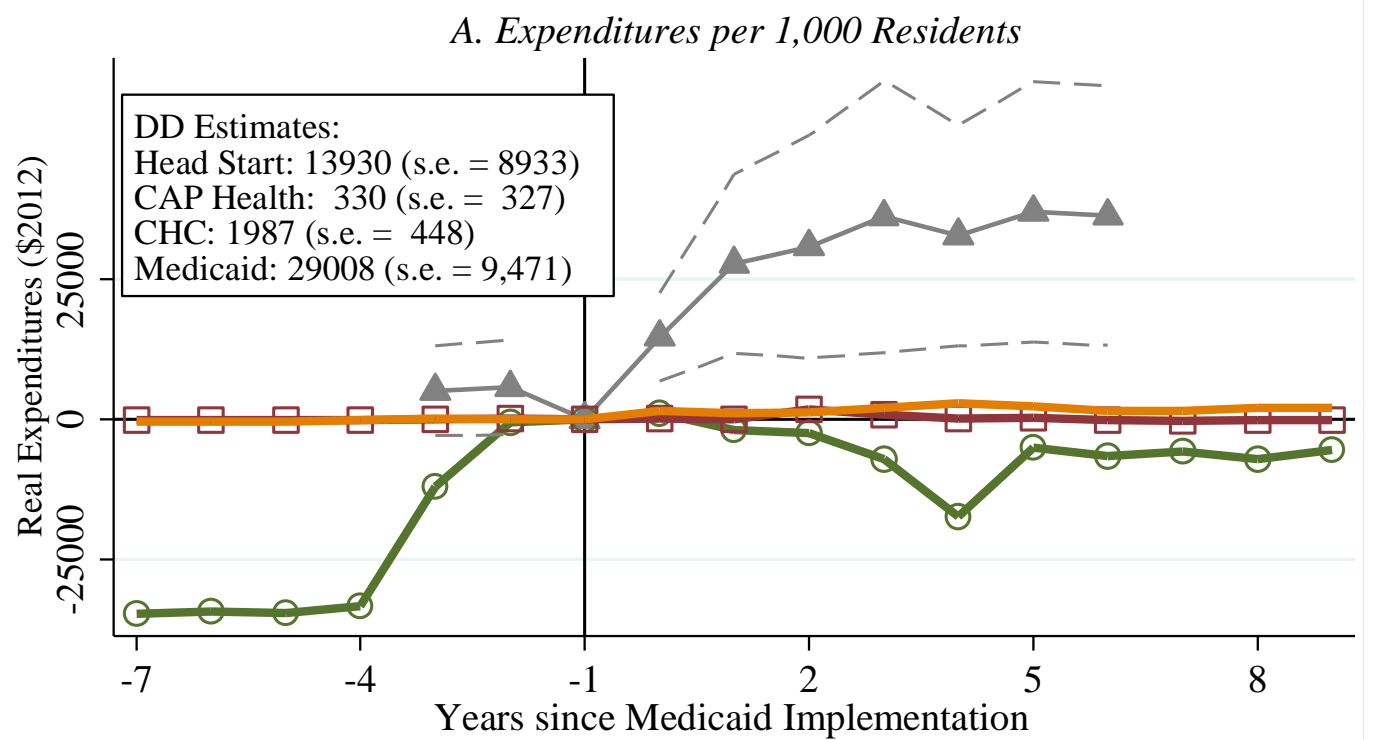
Public Insurance (w/ Medicaid) per 1,000 Children 0-19
$\square$ CAP Health
Head Start per 1,000
Children 1-9

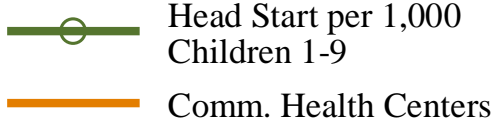

\section{B. Per-Capita Cases}

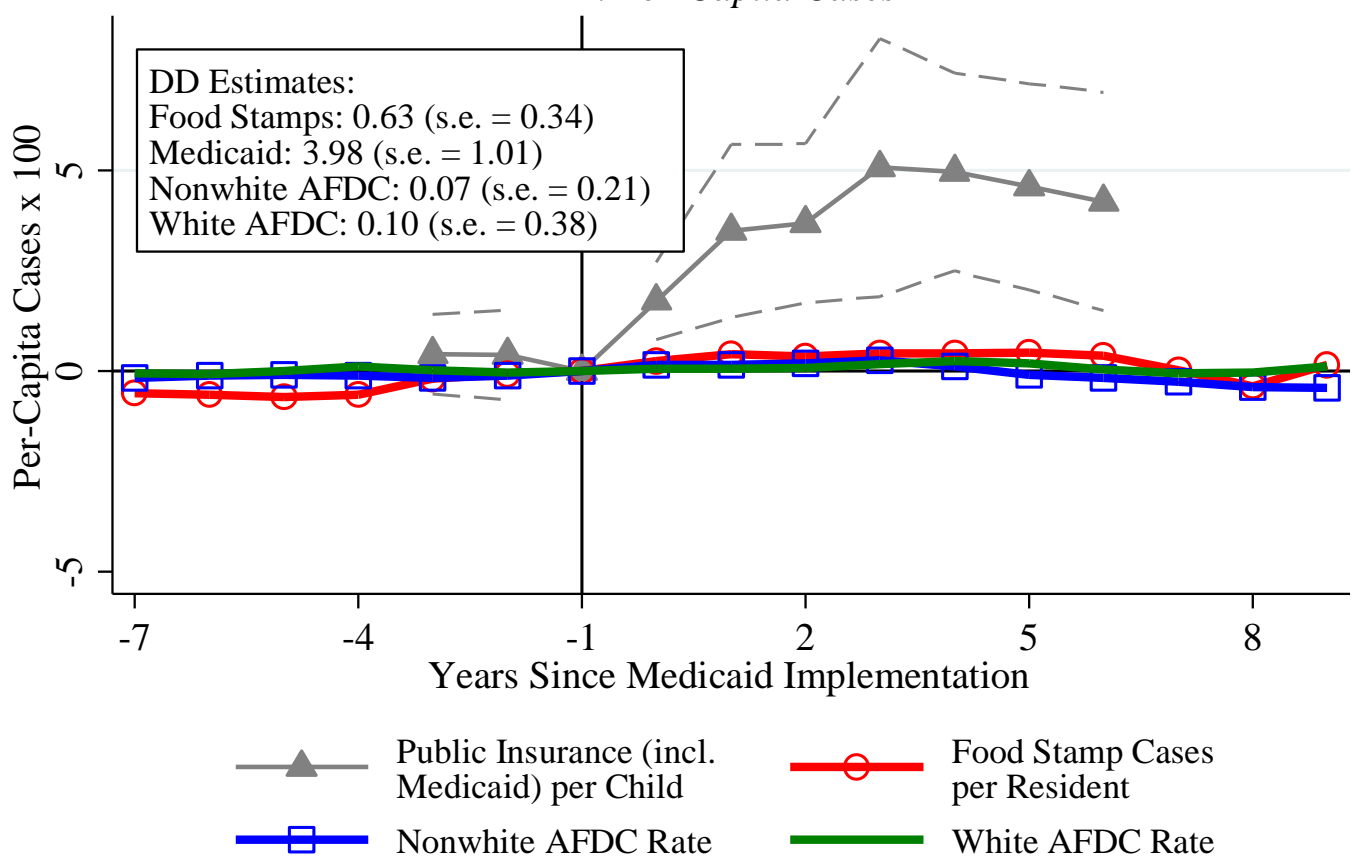

Notes: The figure plots estimated coefficients on interactions between Medicaid timing dummies and $A F D C_{s}^{*}$ in a regression model described in Section III. The dependent variable in panel A is funding per capita (in 2012 dollars) and the dependent variable in panel B is the number of cases per resident or the number of children who used public insurance per child 0-19 (measured from 0-100). The sample for other program funds contains 1,008 observations on 48 states from 1959 to 1979. The results show that other federal health programs or programs that have been shown to affect health outcomes (Head Start: Ludwig and Miller 2007; Community Health Centers: Bailey and Goodman-Bacon 2015; Food Stamps: Almond, Hoynes, and Schanzenbach 2012) did not grow coincidentally with Medicaid in higherAFDC states. Sources: National Archives Community Action Program and Federal Outlays Files, Public Health Service Reports, DHEW (1963-1976) and (HHS 2012). I thank Hilary Hoynes for sharing the Food Stamp caseload data. 
Figure 10. The Proportional Effects of Medicaid on the Mortality Rates of Newly Insured Recipients: Average Treatment Effects on the Treated (ATET)

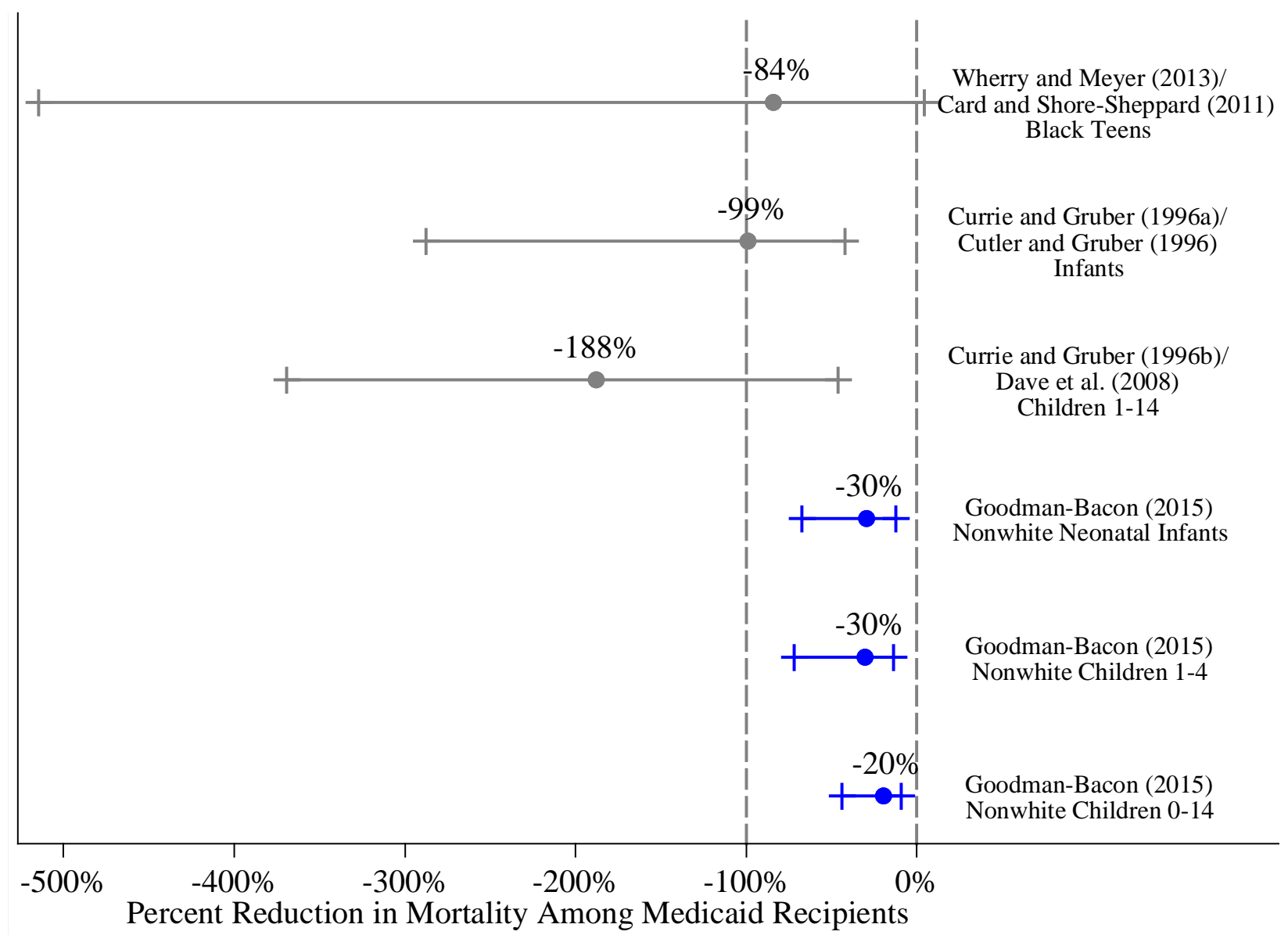

Notes: The figure plots the implied average treatment effects on the treated (ATET) and 95-percent confidence intervals for three comparable previous studies and for the DD results emphasized in this paper: all nonwhite children ages 0-14, nonwhite neonatal infants, and younger nonwhite children ages 1-4. To calculate the ATET, the reduced-form ITTs are expressed as proportional changes in mortality rates, divided by a first-stage estimate for any insurance coverage (adjusted for under-reporting when appropriate), then adjusted for differential baseline mortality among poorer Medicaid recipients. The rightmost column lists the source of the mortality/first-stage estimates (see appendix tables 4.1-4.5 for the parameters). The vertical dashed line at zero indicates that Medicaid does not reduce mortality, and at $-100 \%$ indicates the largest possible value of the ATET (because a group's mortality rate cannot be reduced by more than its baseline level). The 95-percent confidence intervals are generated using a modified percentile method from 10,000 replications of a parametric bootstrap procedure (Johnston and DiNardo 1997, Efron and Tibshirani 1993, Valetta 1993). I generate bootstrap draws of the reduced-form and first-stage coefficients from normal distributions with means and standard deviations equal to the point estimates and standard errors reported in each paper. The confidence intervals are generated by taking the $5^{\text {th }}$ percentile of the empirical distribution of the ATET for draws below the point estimate and the $95^{\text {th }}$ percentile of the empirical distribution above the point estimate. See appendix 4 for details on the bootstrap procedure and alternative estimators for the confidence intervals. 